\title{
Cambio institucional y sociedad esclavista: la intensificación del mercado de trabajo esclavo en Matanzas (Cuba), 1755-1810
}

\author{
AleXANder UrRego Mesa
}

PALABRAS CLAVE: cambio institucional, plantación esclavista, mercado de trabajo esclavo, Matanzas (Cuba).

CÓDIGOS JEL: N96, J21, J43, J47.

$E$ análisis institucional de largo plazo ha fosilizado las transformaciones institucionales en Cuba creando la imagen de una sociedad esclavista para todo el periodo colonial. La historiografía sobre la esclavitud, aunque señala el proceso de cambio, no ha definido sus características y etapas. Este artículo busca comprender la formación de la sociedad esclavista cubana, situar históricamente las transformaciones hacia la economía de plantación en las últimas décadas del siglo XVIII y describir sus características. Para alcanzar estos objetivos se analiza el cambio institucional y el dinamismo económico resultante a partir del marco teórico de los órdenes sociales propuesto por North, Wallis y Weingast (2009), y se hace un estudio empirico del mercado de trabajo esclavo a partir de los registros parroquiales de la catedral de San Carlos de Matanzas (Cuba) entre 1755-1810. Los resultados apuntan a la década de 1780 como el periodo de las principales transformaciones en la disponibilidad de fuerza de trabajo negra y de crecimiento del número de propietarios; y a la década de 1790 como el periodo de la implantación de las características del sistema de plantación, con masivas importaciones de mano de obra masculina y el crecimiento del tamaño de las explotaciones. Se valida el estudio del mercado de trabajo esclavo para el análisis del cambio institucional y del nacimiento de la sociedad esclavista. 


\title{
Institutional changes and slave society: the slave labour market intensification in Matanzas (Cuba), 1755-1810
}

\author{
KEYWORDS: institutional changes, slave plantation, slave labour \\ market, Matanzas (Cuba).
}

JEL CODES: N96, J21, J43, J4.

he long term institutional approach has created a static view of Cuba as a
slave society throughout the entire Colonial period. This ossification of insti-
tutional change in Cuba has been criticized by the historiography on slavery, which has still to define the characteristics and timing of changes in slave ownership. The aim of this article is to understand the rise of a slave society in Cuba, to analyse temporal aspects of the transformation towards a plantation economy in the last decades of the eighteenth century, and to describe its main features. For this purpose, the institutional changes and resulting economic growth are analysed using the social orders framework proposed by North, Wallis and Weingast (2009). The slave market is studied with empirical data from the church records of the San Carlos cathedral in Matanzas, Cuba, and span the 1755-1810 timeframe. The data indicate that the 1780s were a time of increasing black workforce availability and growing numbers of slave owners; while the 1790s involved the establishment of the plantation system, along with a massive influx of male labourers and the expanding size of plantations. This lends support to the use of the slave labour market for institutional change analysis and the genesis of a slave society.

\section{Premio Historia Agraria 2016}

Este artículo obtuvo el XI Premio de Historia Agraria a trabajos realizados por jóvenes investigadores referidos a la historia agraria, la economía y la sociedad rurales, desde una perspectiva interdisciplinar.

Recepción: 2017-01-18 • Revisión: 2017-10-02 - Aceptación: 2017-10-03

Alexander Urrego Mesa [orcid.org/0000-0002-8256-0321] es estudiante del programa de doctorado en Historia Económica en la Facultat d'Economia i Empresa de la Universitat de Barcelona. Dirección para correspondencia: Departament d'Història i Institucions Econòmiques, Universitat de Barcelona, Av. Diagonal, 690, torre 2, 4. ${ }^{a}, 08034$ Barcelona (España).E-mail: alex.urrego.mesa@ub.edu 


\section{INTRODUCCIÓN}

A finales del siglo XviII la isla de Cuba sufrió una serie de transformaciones institucionales que acabaron con una reformulación del pacto colonial entre las élites locales y la corona. Estos cambios afectaron la estructura de la propiedad, la producción agraria y el crecimiento y composición de la población, convirtiendo la isla en la principal productora de azúcar colonial del mundo (Moreno, 2001 [1964]: 74). Antes de este periodo la economía cubana se basó en la ganadería, la manufactura, la venta de cueros, tabaco, la construcción de barcos (Funes, 2008: 20-28) y otras actividades ligadas al desarrollo de la isla como lugar de defensa y puerto de escala.

Aunque esta transformación ha sido desatacada en investigaciones anteriores -que son un clásico de la historiografía cubana (Moreno 2001 [1964]: 7-49), de América y el Caribe (Klein, 1986) - y en trabajos recientes (Bergad, 2007: 12-21; Santamaría, 2014: 169), todavía no se ha hecho un análisis empírico que permita caracterizar el periodo de transición y que sirva de contraste para leer los cambios institucionales que se han identificado en los estudios. Incluso enfoques como el de la New Institutional Economics (NIE) han pasado por alto estos cambios en sus análisis.

La NIE ha vinculado la configuración de altos grados de desigualdad inicial o instituciones extractivas tempranas con el desarrollo económico contemporáneo de Cuba, poniendo el foco en las repercusiones de largo plazo de la esclavitud (Sokoloff \& Engerman, 2000; Acemoglu, Johnson \& Robinson, 2001; Eltis, Lewis \& Sokoloff, 2004). Esta postura homogeniza las sociedades del Caribe a lo largo de toda la historia de la colonia haciendo de Cuba una sociedad esclavista desde el primer momento de la colonización, aspecto reforzado por la historiografía esclavista centrada en el siglo XIX (García Álvarez \& Santamaría, 2004: 504-514).

Los primeros análisis del sistema esclavista en Cuba abordaron la estructura productiva, instituciones como la organización del trabajo, los grupos sociales y otros elementos estructurales para explicar el surgimiento y consolidación del sistema de plantación esclavista hasta su extinción (Moreno, 2001 [1964]; Pérez de la Riva, 1970; Scott, 1985). Estos trabajos sopesan causas externas, como el mercado del azúcar y los conflictos entre las potencias, e internas, como la reformulación de la relación élites-corona y la introducción de reformas para aprovechar las coyunturas favorables (Marrero, 1984; Moreno, 2001 [1964]).

Dentro de estos análisis de largo plazo con un enfoque más cuantitativo se construyeron las cifras sobre la migración forzada. Las series de importaciones de esclavos 
(Curtin, 1969; Eltis, 1987, 2010) permiten observar características generales del proceso, entradas esporádicas, aumentos drásticos y estabilización, entre finales del XVIII y las primeras décadas del siglo XIX. Por su parte, los análisis demográficos (Eblen, 1975; Tornero, 1996: 109-140) muestran el impacto de estas entradas de esclavos sobre la estructura y composición de la población. En el comercio de esclavos también destacan estos cambios. Las series de precios entre 1792-1880 (Bergad, 1987; Bergad, García \& Barcia, 1995) muestran un aumento durante el periodo del despegue azucarero para La Habana, Santiago y Cienfuegos. También se ha resaltado la transformación de las estrategias de comercialización de los esclavistas tras la liberalización de la trata (1789) en Santiago de Cuba (Belmonte, 2010) y la vinculación entre azúcar y esclavos en Trinidad (Chaviano, 2013) desde un enfoque más cualitativo.

A nivel espacial los análisis suelen exaltar el dinamismo de la zona occidental. El caso de La Habana marca la dirección del proceso sin entrar en el estudio de la región de Matanzas (García Rodríguez, 2006), principal zona de producción de azúcar de plantación del siglo XIX en Cuba. El principal estudio de esta última región (Bergad, 1990) también pasa rápidamente sobre el periodo inicial de formación de la sociedad esclavista, ya que su objetivo son las características de la sociedad esclavista del siglo XIX. Entre los estudios, el análisis del periodo de ruptura suele abordarse de forma general y a partir del ultimo cuarto del siglo XviII. El estudio de las características de la economía de plantación del siglo XIX ha jugado en detrimento del análisis del periodo inicial de cambio.

A diferencia de estos trabajos, los análisis más «institucionalistas» se centran en los cambios de regulación que posibilitaron el surgimiento del sistema de plantación de finales del siglo XVIII. Belmonte (2014) y Schneider (2015) han analizado la relación entre el reformismo borbónico y el proyecto esclavista. En esta línea se argumenta que desde el punto de vista de la corona, el tráfico de esclavos permitió reforzar la defensa de la isla, aportar mano de obra para el desarrollo de la agricultura y asegurar la lealtad de las élites locales, trastocada durante la invasión inglesa (Schneider, 2015). Del mismo modo Arteaga (2017) ha mostrado que la amenaza británica llevó a la corona española a crear nuevas rutas comerciales e incorporar élites regionales para mantener las rentas derivadas del comercio.

Los estudios sobre el sistema de plantación esclavista en Cuba presentan información que apunta a finales del siglo XVIII como el momento de cambio. Aunque algunos de ellos han identificado cambios significativos en el marco institucional que impulsaron el desarrollo del proyecto económico de las élites locales, ninguno ha presentado un análisis detallado de este primer periodo de cambios para conocer sus características. Tampoco se han usado los datos conocidos para ofrecer un contraste empírico del éxito que tuvieron estos cambios institucionales. 
El análisis del proceso de formación de la sociedad esclavista en la región de Matanzas es un ejemplo relevante. El territorio pasó de ser un lugar de aprovisionamiento de maderas y ganado para La Habana, basado en una economía de subsitencia familiar vinculada a la producción de tabaco hasta bien entrado el siglo XVIII, a convertirse en la principal zona de producción de azúcar de plantación de la isla durante el siglo XIX (Bergad, 1990). La intensidad, el exito y la escasez de estudios sobre la región, hacen del caso de Matanzas un objeto de estudio relevante para comprender los rasgos generales del proceso de cambio hacia la agricultura de plantación esclavista. La parte norte de la provincia de Matanzas (Fig. 1) fue donde se asentó el núcleo principal de poblamiento y actualmente es la zona de mayor densidad de población de la provincia (ONEI, 2014).

\section{FIGURA 1}

\section{Provincia de Matanzas y zona de estudio}

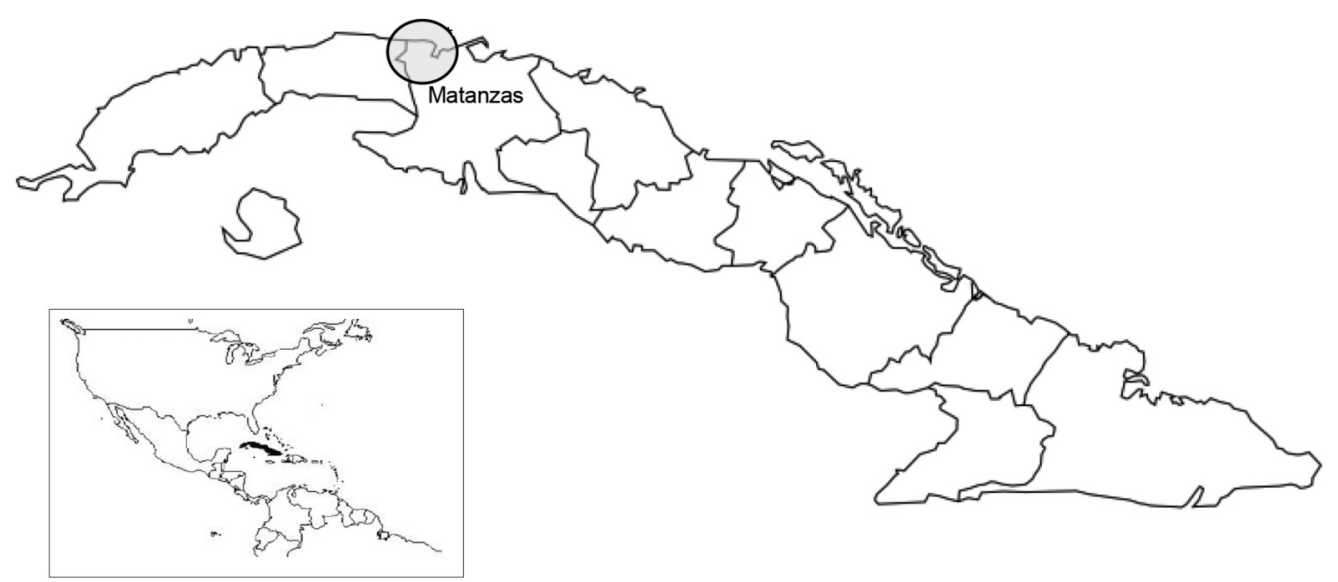

Fuente: elaboración propia.

Este artículo aporta nueva información sobre el proceso de formación de la economía de plantación que tuvo lugar durante la segunda mitad del siglo XvIII en Cuba, analiza las transformaciones institucionales que llevaron a la implantación del modelo esclavista y estudia los cambios en la estructura del mercado de trabajo esclavo en la ciudad de Matanzas. Para ello, introduce el marco del cambio institucional y los órdenes sociales propuesto por North, Wallis y Weingast (2009) y propone un análisis empírico de la evolución del mercado de trabajo esclavo en Matanzas entre 1755-1810.

El análisis institucional aborda la formación de la sociedad esclavista como un proceso de aglutinamiento de las élites en torno a un proyecto común: la explotación de la mano de obra esclava y la producción de azúcar. El apoyo institucional a este proyecto a través de la regulación de la propiedad, los beneficios a la producción de azúcar o la li- 
beralización del comercio y la trata, entre otros, garantizó el dinamismo económico de la isla, proveyendo rentas a las élites locales y estabilidad política a la monarquía.

El análisis empírico del mercado de trabajo esclavo permite identificar las características y periodos del proceso a partir de los datos de los registros parroquiales de la catedral de San Carlos de Matanzas (Cuba). El contexto político internacional y las transformaciones institucionales internas se relacionan con el comportamiento de la disponibilidad de la fuerza de trabajo negra (oferta) y la capacidad de absorción de la mano de obra (demanda) ${ }^{1}$.

Los resultados obtenidos confirman empíricamente el éxito del modelo esclavista y evidencian sus características. Se observa que la década de 1780 es el periodo de las principales transformaciones, tanto en la disponibilidad de fuerza de trabajo negra como en el crecimiento del número de propietarios, y la década de 1790 es cuando tiene lugar la implantación de las principales características del sistema de plantación, con masivas importaciones de mano de obra masculina y el crecimiento del tamaño de las explotaciones esclavistas.

En la siguiente sección se introduce el contexto histórico de la región de Matanzas. La sección tres aborda el problema del cambio institucional y la confluencia de las élites en torno al proyecto esclavista. La sección cuatro corresponde al análisis empírico del mercado de trabajo esclavo en Matanzas; se presentan los datos, la metodología y se analizan los principales resultados. Finalmente se concluye y se anexan las series construidas.

\section{CONTEXTO HISTÓRICO DE LA REGIÓN DE MATANZAS}

El proceso de adjudicación de mercedes de tierras en lo que es hoy la provincia de Matanzas puede remontarse al siglo XVI, pero no es hasta el 12 de octubre de 1693 cuando se funda la ciudad de San Carlos y San Severino de Matanzas con el objetivo de fortificar y asegurar la bahía. Ese año se asignan seis leguas como área de jurisdicción de la nueva ciudad $\left(25-30 \mathrm{~km}^{2}\right)^{2}$. El área comprendía los corrales, hatos y sitios de Yumurí,

1. El término mano de obra esclava está asociado a la capacidad de absorción (demanda) y se refiere únicamente a la población con esta condición jurídica, independiente de su condición racial. Además, se usa el término fuerza de trabajo negra para hacer referencia al conjunto de individuos registrados en los libros de pardos y morenos, incluye población libre y esclava, e informa sobre la oferta total de fuerza de trabajo. Para más detalles, véase la sección 4.1.

2. Para Matanzas, se hace referencia a una treintena de familias canarias que habrían formado el núcleo central (SAN MARFUL, 2007: 312, 326; BERGAD, 1990: 9). Véanse los expedientes de pobla- 
Corral Nuevo, Caunabaco, el corral de Matanzas, San Agustín, el sitio de Aguacate, La Magdalena, San Pedro, Limones Chicos, Caoba, Laguna de Palos, y el hato de Canímar (San Marful, 2007: 311, 325). Hatos y corrales fueron asignados como merced a lo largo de los siglos XVI y XVII para el cuidado de ganado mayor y menor con una extensión de dos y una legua, respectivamente. Estas delimitaciones marcaron la división administrativa futura y fueron fuente de pleitos por derechos de propiedad sobre la tierra.

A lo largo del siglo XVII la economía de la región se caracterizó por su ganadería primitiva, la explotación de maderas para la construcción de navíos en La Habana y la agricultura de subsistencia, complementada con un creciente cultivo del tabaco en pequeñas explotaciones familiares a partir de 1690. El impulso del tabaco, según afirma Bergad (1990: 3-17), fue estimulado por el interés de las élites. Con la construcción de dos manufacturas en 1715 y 1717 el marqués Justis de Santa Anna y el conde de Gibacoa monopolizaron el procesamiento y comercialización, garantizando así un mercado regular para la producción de los vegueros. La influencia política de estas élites mantuvo los deseos de intervención de la corona bajo control, a pesar del monopolio teórico establecido entre 1717 y 1724 . Sin embargo, el interés de las élites por el azúcar y la reimplantación del monopolio en 1761 contribuyeron al debilitamiento de esta industria durante la segunda mitad del siglo (Bergad, 1990: 11-15).

Hasta este momento el peso de la economía azucarera en la provincia era mínimo. La jurisdicción contaba con cinco ingenios en 1778 y ocho en 1792 que producían un 1,5\% del total de azúcar de la isla (San Marful, 2007: 328). No obstante, en 1798 el puerto de Matanzas daba salida al azúcar de 22 ingenios ubicados en el naciente cinturón azucarero entre Corral Nuevo y Guanábana (Moreno, 2001 [1964]: 120). Aunque el dinamismo creciente fue acompañado por la habilitación provisional del puerto de Matanzas en 1793, no fue hasta 1809 cuando se obtuvo el permiso para el comercio libre (Sagra, 1831: 181-182). El impulso del sistema de plantación esclavista en la región fue tal que en 1827 entre ingenios y trapiches se cuentan 111 sitios dedicados a la producción de azúcar (Marrero, 1984: 89) que contribuían con el $25 \%$ de la producción total de la isla (Moreno, 2001 [1964]: 121).

Otro indicador de este proceso de cambio es la disponibilidad de fuerza de trabajo vinculada al éxito del modelo azucarero, mayoritariamente esclavos y negros libres durante esta etapa. La comparación de la evolución de la población de Matanzas con el resto de

ción y fortificación del puerto de Matanzas (Archivo General de Indias [AGI], Santo_Domingo, 457 y Santo_Domingo, 869, L.7203V-205R). 
Cuba confirma la tendencia general de cambio y resalta la relevancia de la región de Matanzas. Para el conjunto de la isla, el crecimiento de la población por grupos fue generalizado. En el primer periodo (1774-1792) destaca el protagonismo de la población negra libre y esclava. A partir de 1792 el crecimiento de los libres se estanca y luego empieza a caer, a diferencia de la población esclava que se mantiene hasta el final del periodo y alcanza el nivel de la población blanca (Gráfico 1).

\section{GRÁFICO 1}

Evolución de la población por grupos sociorraciales en Cuba, 1774-1827

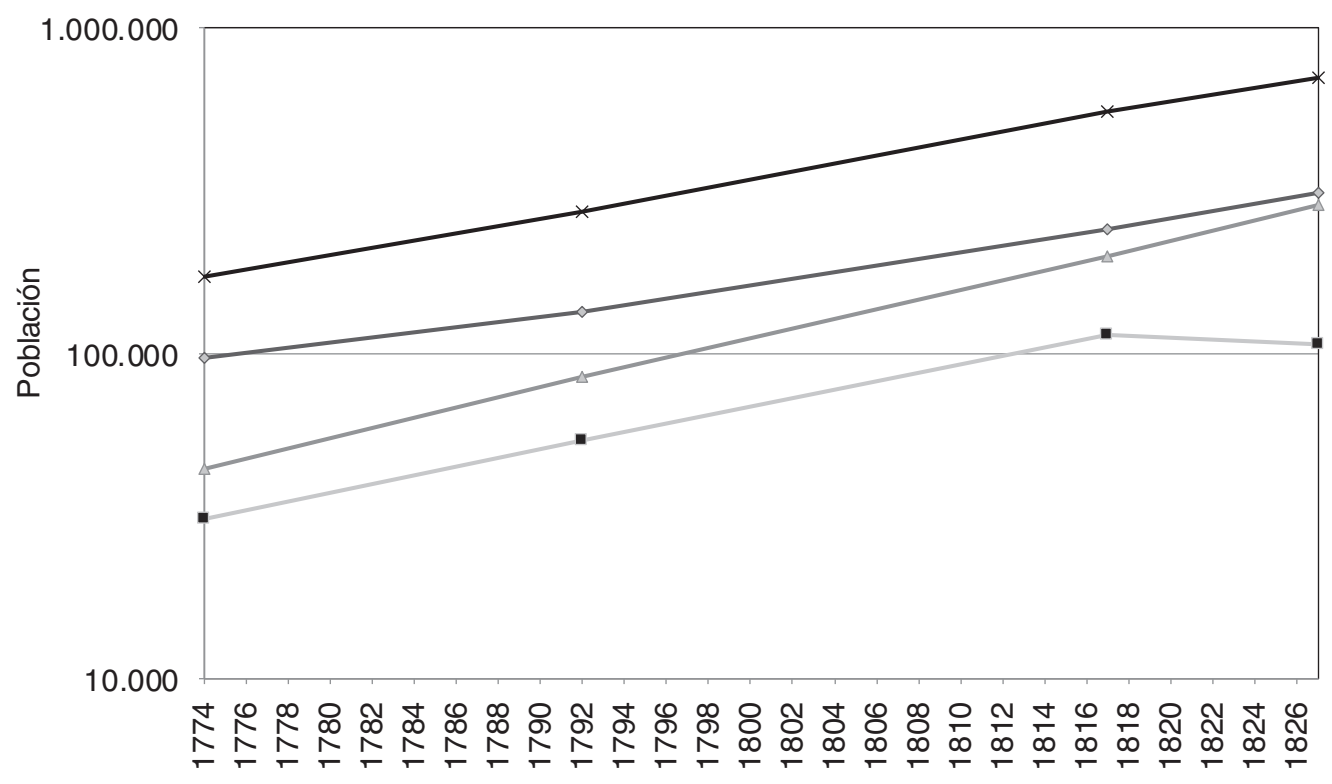

Años

$\neg$ Blancos libres - - Negros y morenos libres

$\triangle$ Negros y morenos esclavos $*$ Total

Fuente: elaboración propia a partir de Sagra (1831).

Para el caso de la provincia de Matanzas, se observa la misma tendencia general de crecimiento liderada por negros libres y esclavos en el primer periodo y un aumento más tímido entre los blancos (Gráfico 2). Después de 1792 el ritmo de crecimiento lo marca la población esclava. Con respecto a Cuba, hay que remarcar que el crecimiento no parece estancarse en ningún momento y la intensidad es mucho más pronunciada, especialmente en el periodo final. Este dinamismo se refleja en el crecimiento de la proporción que representa la población de Matanzas respecto de la de la isla, que pasa del $2 \%$ en $1774 \mathrm{al}$ 7\% en 1827 . Los esclavos no solo superan a la población blanca, sino que además en 1827 representan el $9 \%$ del total de esclavos de Cuba. 


\section{GRÁFICO 2}

Evolución de la población por grupos sociorraciales en Matanzas, 1774-1827

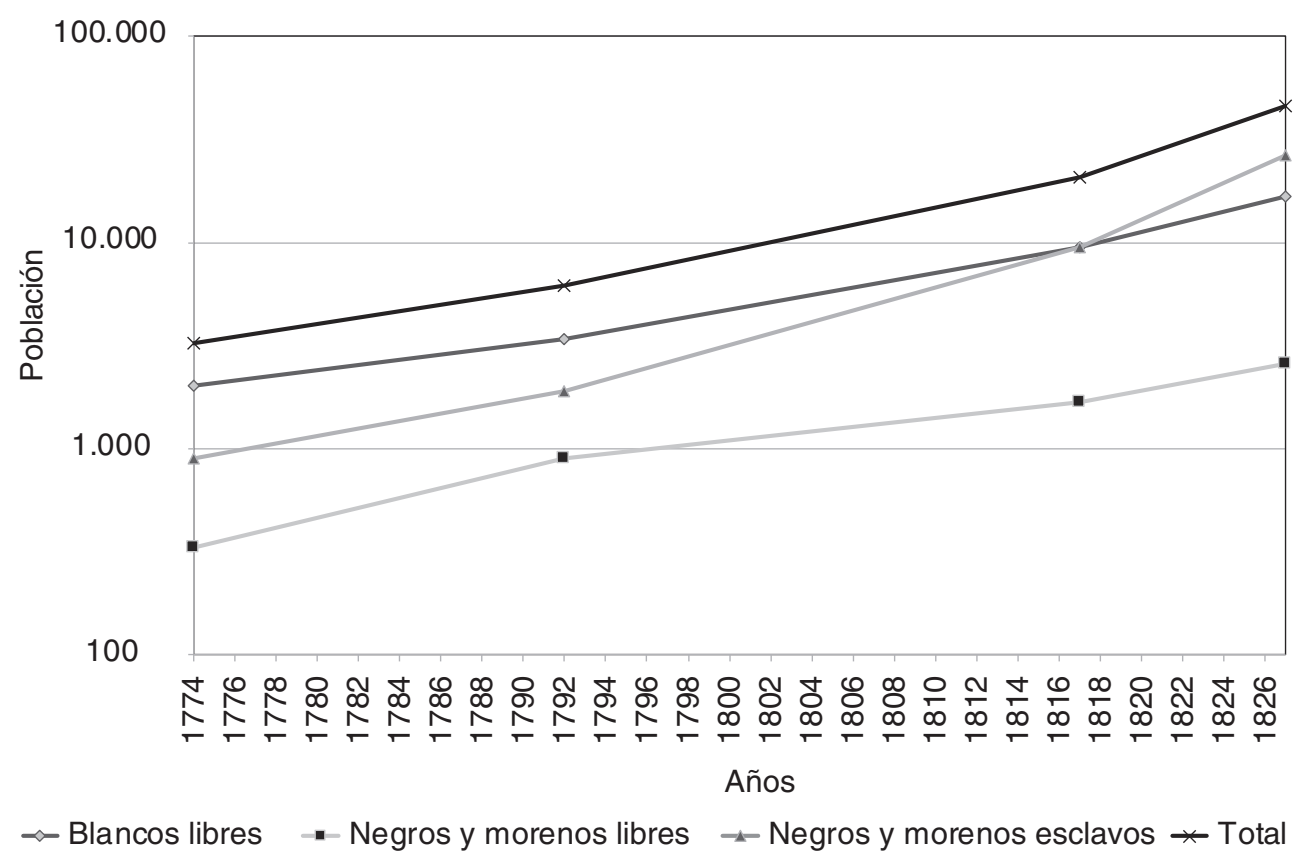

Fuente: elaboración propia a partir de Sagra (1831).

En términos generales se puede decir que la región de Matanzas está experimentando unas transformaciones demográficas mucho más intensas que el resto de la isla a fínales del siglo XVIII, particularmente entre la población esclava. La desaceleración del crecimiento en el conjunto de Cuba del final del periodo está ligada al desarrollo temprano del azúcar en la zona de La Habana. Es posible que la ruptura que se percibe en Matanzas ya se hubiera producido en La Habana y por tanto las posibilidades de crecimiento allí serían más limitadas. También se puede pensar en una transformación más tardía y menos intensa en las zonas del centro y el oriente. En cualquier caso, es en Matanzas donde las transformaciones demográficas que indican el paso al modelo azucarero son más intensas para este periodo. 


\section{CAMBIO INSTITUCIONAL Y NACIMIENTO DEL MODELO AZUCARERO}

\subsection{Desigualdad institucional y dinamismo económico}

En Violence and Social Orders, North, Wallis y Weingast (2009) ofrecen un marco teórico sobre la configuración y evolución institucional de las sociedades a partir del control de la violencia. Distinguen entre sociedades de acceso limitado (SAL) o estados naturales, donde se usa el sistema político para regular la competencia económica y generar rentas a las élites, y sociedades de acceso abierto (SAA), que garantizan la formación de organizaciones y el desarrollo de intercambios impersonales.

En oposición al análisis de causalidad de largo plazo entre la configuración institucional temprana, su permanencia y el desarrollo económico actual que propone la NIE para el análisis de las regiones en desarrollo (Sokoloff \& Engerman, 2000; Acemoglu, Johnson \& Robinson, 2001), la teoría de los órdenes sociales y el cambio institucional facilita el análisis histórico. Las SAA son un fenómeno del siglo XIX y sólo un $15 \%$ de la población mundial vive en ellas (North, Wallis \& Weingast, 2009), siendo la desigualdad institucional la regla para el pasado y gran parte de la población mundial actual. En este sentido, el análisis de permanencias en el largo plazo que propone la NIE dificulta la explicación de las dinámicas - políticas y económicas- del cambio histórico.

Las SAA aseguran la entrada libre de todos los miembros de la sociedad a la política y los mercados a través de instituciones formales (ley), garantizando la inversión en educación, salud, infraestructuras y el aumento de los intercambios impersonales. Así se consigue una mayor integración de mercados, división del trabajo y especialización, lo que contribuye al crecimiento y desarrollo económico. La estabilidad de este orden deriva de la interiorización de los valores de libertad que se promueven.

Por su parte, las SAL, más interesantes para nuestro análisis, restringen el acceso a la política y los mercados. El monopolio del poder económico sirve para ofrecer rentas a las élites que dan soporte político -o se abstienen del uso de la violencia- y conseguir estabilidad. A su vez, el acceso restringido a la política asegura la distribución económica desigual y el apoyo formal a los intereses económicos de las élites. Aunque la coalición de las élites limita el acceso a recursos (tierra, trabajo o capital) y actividades (comercio o educación), la estabilidad política permite el desarrollo de un ambiente macroeconómico favorable a la inversión. 
El orden social limitado se divide en frágil, básico y maduro, según la disponibilidad de un recurso en torno al cual las élites puedan articular un proyecto económico común y el grado de apoyo de las instituciones formales a este proyecto. Para la explotación de este recurso, las organizaciones políticas y económicas deben estar apoyadas en instituciones que limiten el uso arbitrario del poder, permitan el desarrollo de intercambios impersonales, como la regulación de la propiedad, reduzcan las barreras de entrada a los mercados y garanticen inversiones en infraestructuras, como la construcción de puertos y otras vías de salida de productos.

El impulso del crecimiento económico en un orden limitado genera una serie de contradicciones. Cambios como la liberalización del acceso a los mercados o la inversión en educación, que pueden aumentar la producción, la productividad y la base fiscal, también impulsan el crecimiento de nuevas clases sociales con poder económico que amenazan el statu quo. La inestabilidad del control de la violencia abre la puerta a la reconfiguración de pactos como una herramienta de dinamismo económico y estabilidad política.

\subsection{Cambio institucional y sociedad esclavista}

Los cambios acontecidos en Cuba entre finales del siglo XVIII y principios del XIX responden a estímulos externos marcados por los conflictos entre las potencias coloniales vinculadas al comercio del azúcar, el estancamiento de la producción en las islas inglesas a causa del agotamiento de las tierras (Moreno, 2001 [1964]) y el aumento de los precios del azúcar (Marrero, 1984: 152; Eltis, Lewis \& Richardson, 2005: 679, 682). Estas trasformaciones institucionales internas relacionadas con la renovación del pacto colonial entre la corona y las élites locales se formalizaron en regulaciones sobre la liberalización del mercado de tierras, del comercio, la trata y otros beneficios a la plantación.

El aumento de la riqueza de la nación por medio del crecimiento de la población y la producción agraria fue un objetivo común de las monarquías europeas durante el siglo XVIII. En este contexto, Campomanes, que reconocía la importancia de los esclavos en el desarrollo del tabaco en Virginia y Maryland, abogaba por un puerto de comercio de esclavos libre de impuestos en las islas Canarias para introducir esclavos en América (Schneider, 2015). La invasión inglesa de Cuba (1762) eliminó temporalmente (11 meses) todas las trabas al comercio de esclavos y puso en evidencia la lealtad de las élites locales, que colaboraron con las autoridades inglesas mientras duró la ocupación (Schneider, 2015). Ante este nuevo escenario el proyecto esclavista de la corona tomo un nuevo impulso y un nuevo significado. 
Según North, Wallis y Weingast (2009: 21), en las SAL los cambios pueden afectar la distribución de la violencia potencial y llevar a una renegociación de la distribución de privilegios y rentas dentro de las coaliciones de clases dominantes. La tensión política entre monarquía y élites locales se resolvió con garantías para el desarrollo de los intereses económicos de las últimas, que en Matanzas se habían empezado a dirigir hacia el azúcar desde 1760 (Bergad, 1990: 9-11). Se produjeron cambios que facilitaron el desarrollo de la economía de plantación, como la liberalización del mercado de tierras, del comercio y de la trata de esclavos, incluso se concedieron ventajas fiscales. A cambio la monarquía se benefició de los ingresos provenientes del aumento del tráfico comercial (Tornero, 1996; Arteaga, 2017) y la estabilidad política (Schneider, 2015).

El desarrollo de la agricultura comercial atacó viejas instituciones, como mayorazgos, capellanías y mercedes, que mantenían ataduras sobre el mercado de tierras. Una vez desbloqueadas estas restricciones, los terratenientes absentistas obtuvieron la titularidad de grandes extensiones de tierra como hatos y corrales. Los nuevos propietarios consiguieron beneficios partiendo sus tierras y vendiéndolas para convertirlas en ingenios, cafetales o potreros. Además de liberar el mercado de tierras, estos cambios institucionales permitieron la acumulación de capital para la fundación de ingenios (Marrero, 1984: 75-76).

$\mathrm{El}$ aumento del número de fincas es un buen indicador del dinamismo del mercado de tierras. Entre 1778 y 1827 pasaron de 7.578 a 35.117, lo cual representa un crecimiento anual del $3 \%$ durante medio siglo en toda la isla ${ }^{3}$. Este incremento fue más intenso y temprano en la región occidental que en las del centro y el oriente, coincidiendo con el inicio del auge azucarero de finales del siglo XvIII. Entre 1778 y 1792 en el occidente el número de fincas pasó de 3.764 a 8.089, un 67\% del total de las fincas de la isla en el último año (Marrero, 1984).

El interés económico de las élites locales coincidió con el deseo reformista de la corona y su necesidad de afianzar lealtades frente a las amenazas extranjeras, tal como lo reflejan los discursos y análisis de la realidad económica de la isla. O'Reilly en La descripción de la isla de Cuba [...] (1765), Agustín Crame en su Discurso sobre el fomento de la isla de Cuba (1768) y Francisco de Arango y Parreño, «ideólogo» y ejecutor de cambios importantes relativos al comercio de esclavos, coincidían en la importancia de la agricultura, la falta de brazos en la isla y la necesidad de esclavos (Marrero, 1984: 8-9), tal como lo habían apuntado los reformadores.

3. Se ha corregido la tasa de crecimiento anual presentada por L. MARRERO, ya que el autor la estima en 7,4\% para el periodo $1778-1827$ (1984: 77 ). 
Las regulaciones y fomento al comercio de azúcar y esclavos también evidencian esta confluencia de intereses y el apoyo institucional de la corona al proyecto de los plantadores. Algunos cambios favorables al azúcar fueron, la libertad para levantar destilerías a mediados de la década de 1760, el aumento de aranceles para el azúcar extranjero importado a España, que culminó con la promulgación de regulaciones y aranceles para el comercio libre entre España y las Indias (1778) y tres puertos en Cuba (Funes, 2008: 2829), la eliminación de derechos, alcabalas y diezmos al azúcar, café, añil, algodón, aguardiente de caña y ron entre 1768-1804 (Moreno, 2001 [1964]; Marrero, 1984), e incluso la eliminación de restricciones sobre el aprovechamiento de bosques privados entre 1800-1815 (Sagra, 1831: 77-78; Funes, 2008:36-37). En relación con los esclavos se pueden mencionar la fundación de la Compañía Gaditana de Negros (1765), la adquisición de territorio en África occidental para el comercio de esclavos (1778) (Schneider, 2015), los intentos de regulación de las relaciones amo-esclavo (Belmonte, 2014; Lucena, 1996) y la liberalización progresiva de la trata entre 1789 y $1798^{4}$.

El resultado de estas medidas destaca claramente. Las exportaciones de azúcar pasaron de 6.418 toneladas en 1760 a 28.761 en 1800, y en 1792 la isla se convirtió en el tercer productor de azúcar colonial para el mercado internacional (Moreno, 2001 [1964]: 534). Además, el aumento de las exportaciones de productos derivados, como mieles y ron (Moreno, 2001 [1964]; Tornero, 1996) indican cierto nivel de especialización y complejidad técnica asociada al auge del ingenio. Las importaciones de esclavos, que en los años de 1760 no superaron los 600 efectivos, excepto durante la ocupación inglesa, se situaron sobre los 4.500 en 1800, superando los 6.000 en 1791 y 1792 (Eltis, 2010). Este hecho contribuyó notablemente al crecimiento demográfico y los cambios en la estructura de la población.

El aumento de la producción de azúcar está estrechamente vinculado al avance de la plantación desde La Habana hacia la región de Matanzas, la liberalización del mercado de tierras y el aumento de la población esclava. Estos elementos esenciales del proceso de cambio fueron garantizados por la seguridad jurídica que aportó la confirmación de la propiedad, las regulaciones que facilitaron el acceso a los mercados de azúcar y mano de obra esclava, y la buena entente entre las élites locales y la corona.

4. Entre las prohibiciones a la trata se encontraba la de la entrada de esclavos franceses o que hubieran estado en colonias donde hubiera tenido lugar una rebelión de esclavos. 


\section{EVOLUCIÓN DEL MERCADO DE TRABAJO ESCLAVO EN MATANZAS}

\subsection{Fuentes, datos y tratamiento de la información}

Las fuentes utilizadas para describir la evolución de la población esclava han sido los censos de 1774, 1778, 1792, 1817, 1827, el recuento de 1810 (Eblen, 1975; Tornero, 1996) y las mencionadas más arriba sobre migración forzada y el comercio de esclavos. El uso de registros parroquiales ha estado ligado al desarrollo de la nueva historia cultural. Los registros se han usado para estudiar la configuración de las identidades de los esclavos y sus descendientes en Río de Janeiro (Gomes, 2012) y la configuración de las relaciones familiares y de parentesco de los esclavos en Cuba (Meriño \& Perera, 2006, 2008). Aunque se han usado fuentes notariales para el estudio del mercado de trabajo esclavo en el caso de México (Seijas \& Sierra, 2016), no se ha encontrado un precedente sobre el uso de registros parroquiales para analizar el mercado de trabajo esclavo en Matanzas u otra región de Cuba.

Esta propuesta pone el foco en el cambio institucional hacia el esclavismo y lo contrasta empíricamente con los datos de la evolución demográfica de la población esclava de Matanzas. El análisis del mercado de trabajo esclavo aporta nueva información sobre el proceso de formación de la sociedad esclavista para la primera mitad del siglo XVIII en Matanzas, incluida en los análisis generales pero poco estudiada por la historiografía esclavista, especialmente durante esta primera etapa.

El acceso a los registros parroquiales ha sido posible gracias al proyecto «Ecclesiastical Sources and Historical Research on the African Diaspora in Brazil and Cuba", de la Universidad de Vanderbilt, dirigido por la Dra. Jane Lander. El proyecto tiene por objetivos conservar, reunir y difundir fuentes eclesiásticas de la población africana en América, y facilitar el desarrollo de investigaciones sobre las sociedades esclavistas en Latinoamérica ${ }^{5}$.

En este artículo se analizan 9.986 registros de libros de bautismos (1755-1810) y muertes (1762-1810) de la iglesia parroquial de San Carlos de Matanzas (Fig. 1). Se ha recogido información detallada de 4.756 observaciones entre 1755-1770 y 1780-1799, e información agregada de 5.230 observaciones para los periodos 1771-1779 y 1800-1810 con los propósitos de recoger datos sobre grupos de edad, sexo, condición jurídica y nombre de los propietarios, y ofrecer una serie completa del crecimiento de la población negra en Matanzas entre 1755-1810. Los grupos de población que se han identificado en

5. Para más información, véase http://www.vanderbilt.edu/esss/cuba/projects/matanzas.php 
los registros son: negros africanos, criollos y pardos, que pueden ser libres o esclavos, y población blanca en calidad de propietaria de esclavos. Se denomina negros a todas las gamas y designaciones que aparecen en los libros de pardos y morenos, distinguiendo en función del grupo de edad, sexo y condición jurídica.

Se han homogenizado fechas calculando la diferencia de días entre el nacimiento y el bautismo para cada observación y aplicando la media anual de días sin bautizar a cada fecha incompleta (Tabla 1). Las entradas no registradas en los bautismos, como las de agua de socorro, se han clasificado por sexos, grupos de edad y se han sumado a los bautismos (Tablas 1 y 2) con el fin de ofrecer una serie de entradas de población más completa (Gráfico 5$)^{6}$. Para el estudio del número y tamaño de la explotación esclavista se ha estandarizado la ortografía de nombres de los propietarios (Gráfico 6).

La cobertura del registro de nacimientos ha sido testada agrupando la cantidad de niños y niñas bautizados en los periodos para los que se dispone de datos desagregados y calculando la relación de masculinidad ${ }^{7}$. A los datos de niños y niñas bautizados (columnas a y b), se ha agregado la información de bautismos realizados de urgencia en el momento de la muerte o agua de socorro, que constaban en los registros de muerte (columnas $\left.\mathrm{a}^{\star} \mathrm{y}^{\star}\right)$ (Tabla 1$)$.

TABLA 1

Relación de masculinidad y número medio de días sin bautizar entre el nacimiento y el bautismo, 1755-1769/1780-1799

\begin{tabular}{lcccccc}
\hline Años & Niños & Niñas & \multicolumn{2}{c}{ Agua de socorro } & Ratio H/M & Días sin \\
& \multicolumn{1}{c}{$(\mathbf{a})$} & \multicolumn{1}{c}{$(\mathbf{b})$} & Niños $\left(\mathbf{a}^{*}\right)$ & Niñas $\left(\mathbf{b}^{*}\right)$ & $\left(\mathbf{c}=\mathbf{a}+\mathbf{a}^{\star} / \mathbf{b}+\mathbf{b}^{\star}\right)$ & bautizar (d) \\
\hline $1755-1759$ & 68 & 76 & 0 & 0 & 89 & 13 \\
$1760-1764$ & 68 & 91 & 4 & 0 & 79 & 11 \\
$1765-1769$ & 100 & 88 & 2 & 1 & 115 & 9 \\
$1780-1784$ & 124 & 137 & 9 & 3 & 95 & 13 \\
$1785-1789$ & 163 & 165 & 0 & 0 & 99 & 12 \\
$1790-1794$ & 213 & 196 & 7 & 2 & 111 & 12 \\
$1795-1799$ & 228 & 226 & 6 & 4 & 101 & 14 \\
\hline Totales & $\mathbf{9 6 4}$ & $\mathbf{9 7 9}$ & $\mathbf{2 8}$ & $\mathbf{1 0}$ & $\mathbf{1 0 0 , 3}$ & $\mathbf{1 2}$ \\
\hline
\end{tabular}

Fuente: elaboración propia a partir de los libros de bautismos y entierros de la iglesia parroquial de San Carlos de Matanzas.

6. Agua de socorro es la cláusula de referencia cuando, por causa de una muerte prematura, no se había practicado el bautismo.

7. En todas las poblaciones donde no existe aborto selectivo por sexos la relación entre el número de nacimientos de sexo masculino y femenino es constante y de aproximadamente 105 niños por 100 niñas. 
La relación de masculinidad resultante (100; columna c) indica un relativo subregistro de niños sobre el conjunto del periodo; esto probablemente se debe a que el periodo transcurrido entre el nacimiento y el bautismo era considerable (12 días de media; columna d). La mortalidad en las primeras horas y días de vida es muy elevada y generalmente mayor en los niños que en las niñas. Véase que sobre el conjunto del periodo, el número de niños que reciben agua de socorro triplica al de niñas (columna $a^{\star}$ ). La proporción de niños y niñas que recibieron agua de socorro es baja, por lo que suponemos que el registro deficiente de estos niños en mayor proporción que niñas explicaría que la relación de masculinidad de los bautismos del conjunto del periodo sea inferior a 105.

Los valores observados para los intervalos quinquenales son difíciles de interpretar dado que el número de casos es muy reducido y las variaciones aleatorias tienen un gran peso. En general, se confirma que los datos de los registros de la parroquia de San Carlos de Matanzas tienen un grado aceptable de fiabilidad y coherencia interna para aproximar la evolución de los indicadores demográficos de la población negra libre y esclava de la región.

\subsection{La oferta: reproducción y sustitución}

Con el uso de los censos y registros de aduanas se ha podido estudiar el crecimiento total de la población esclava (Eblen, 1975; Tornero, 1996: 109-140) y la evolución de las importaciones de esclavos (Curtin, 1969; Eltis, 2010) de forma general. Esta propuesta permite conocer los dos componentes del crecimiento de la población (crecimiento natural y migratorio) como herramienta para evaluar la evolución de la disponibilidad de la fuerza de trabajo negra (libres y esclavos) y abre la posibilidad de aportar información sobre las etapas del proceso de cambio hacia la plantación esclavista.

La cifra anual de nacimientos de la población negra presenta una tendencia creciente (Gráfico 3). Entre 1755 y 1810 los nacimientos se multiplicaron por tres. En la curva se pueden identificar tres periodos de crecimiento del número de nacimientos (1765-1770, $1780-1796$ y $1800-1810)$ y tres de estabilidad (1755-1765, $1770-1780$ y $1796-1800)$. El número anual de defunciones superó generalmente a los nacimientos, por lo que el crecimiento natural de la población negra fue negativo durante casi todo el periodo, excepto entre 1783-1794 y 1805-1810. Las fluctuaciones anuales son más frecuentes e intensas entre las muertes que entre los nacimientos a causa de los brotes epidémicos registrados (Espinosa \& Beldarraín, 2005). 


\section{GRÁFICO 3}

Evolución anual de los nacimientos, defunciones y crecimiento natural de la población negra de Matanzas, 1755-1810

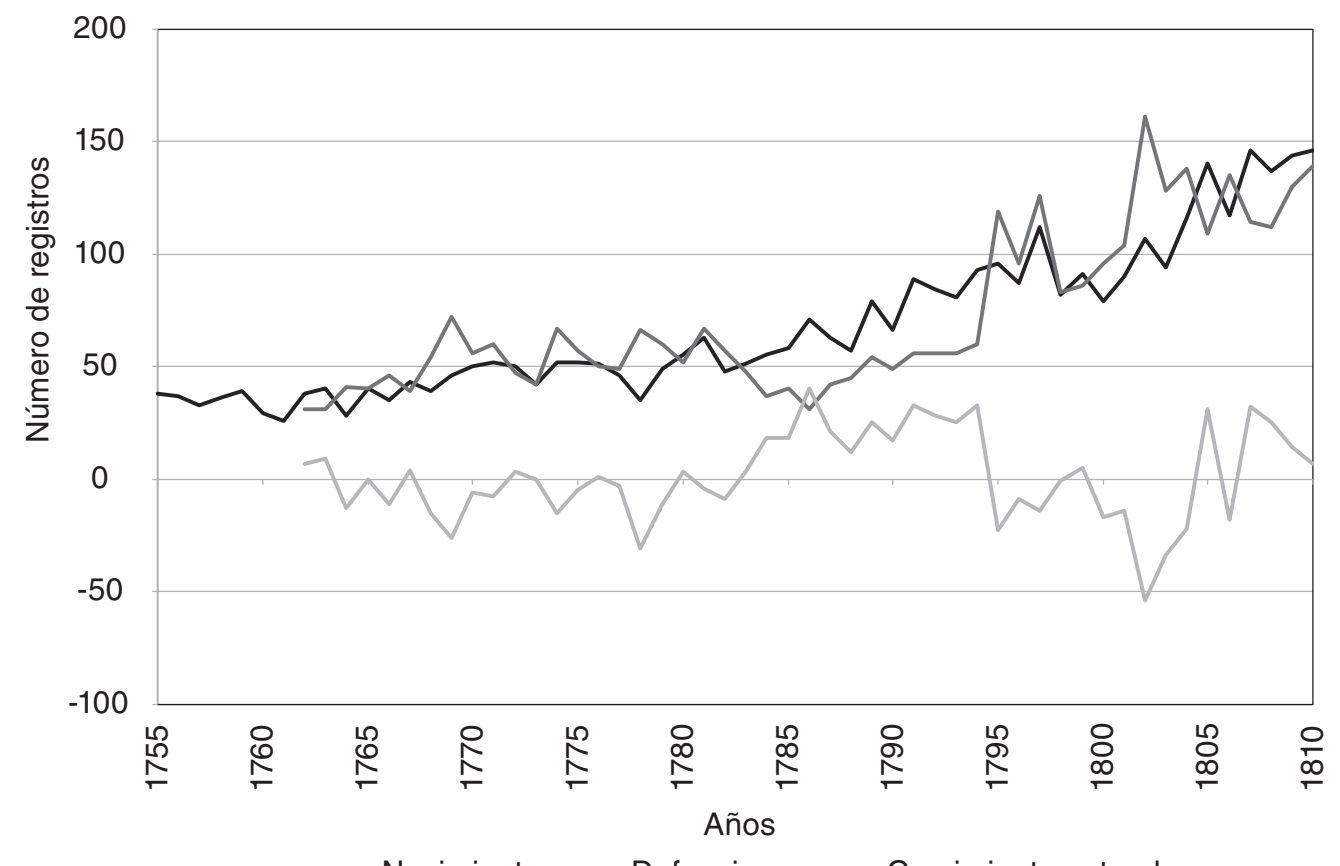

- Nacimientos - Defunciones - Crecimiento natural

Fuente: elaboración propia a partir de los libros de bautismos y entierros de la iglesia parroquial de San Carlos de Matanzas.

Para el cálculo del crecimiento migratorio con los datos de registros, se ha supuesto que la emigración de esclavos de Matanzas fue muy baja. Los motivos para pensar esto son que la expansión de la frontera agrícola se produjo desde La Habana hacia Matanzas, lo cual lleva a que, en caso de haber migración, debería haberse producido en este sentido, y que la movilidad del esclavo dependía de su propietario, así que se espera que el grueso de la población esclava permaneciera en Matanzas con sus amos en un momento de expansión de la actividad azucarera.

Como se observa en el Gráfico 4, el flujo de las importaciones de esclavos en la segunda mitad del siglo XviII se multiplicó por diez y estuvo marcado por fuertes oscilaciones. Estas entradas mayores de población corresponden a un contexto internacional favorable y a transformaciones internas que permitieron el incremento de la fuerza de trabajo negra a través de la trata en tres periodos claramente diferenciados. 
En el primero (1755-1785) las importaciones de esclavos parecen ser más esporádicas y dependientes de coyunturas externas, como la invasión inglesa (1762) o la guerra de Independencia de Estados Unidos (1775-1783). En el segundo (1785-1795) se produce un cambio de tendencia hacia el aumento regular de la inmigración forzada, y el efecto coyuntural de la Revolución francesa en Saint Domingue (1791) parece tener una importancia menor en la llegada de esclavos. El movimiento creciente de la curva parece coincidir más con transformaciones internas de medio plazo, como la liberación progresiva de la trata (1789-1798), la aplicación de medidas favorables a la producción de plantación, como la eliminación de derechos, alcabalas y diezmos al azúcar, café, añil, algodón, aguardiente de caña y ron (1768-1804), y el estímulo del comercio de azúcar, como el aumento de aranceles para el azúcar extranjero importado en España y la promulgación de regulaciones y aranceles para el comercio libre entre España y las Indias (1778), comentadas más arriba. Finamente, en el tercer periodo (1795-1810) se observa cierta estabilización de las entradas masivas de población esclava, que coincidirían con el afianzamiento de estas medidas.

\section{GRÁFICO 4}

Serie anual de entradas por inmigración de esclavos africanos en Matanzas, 1755-1810

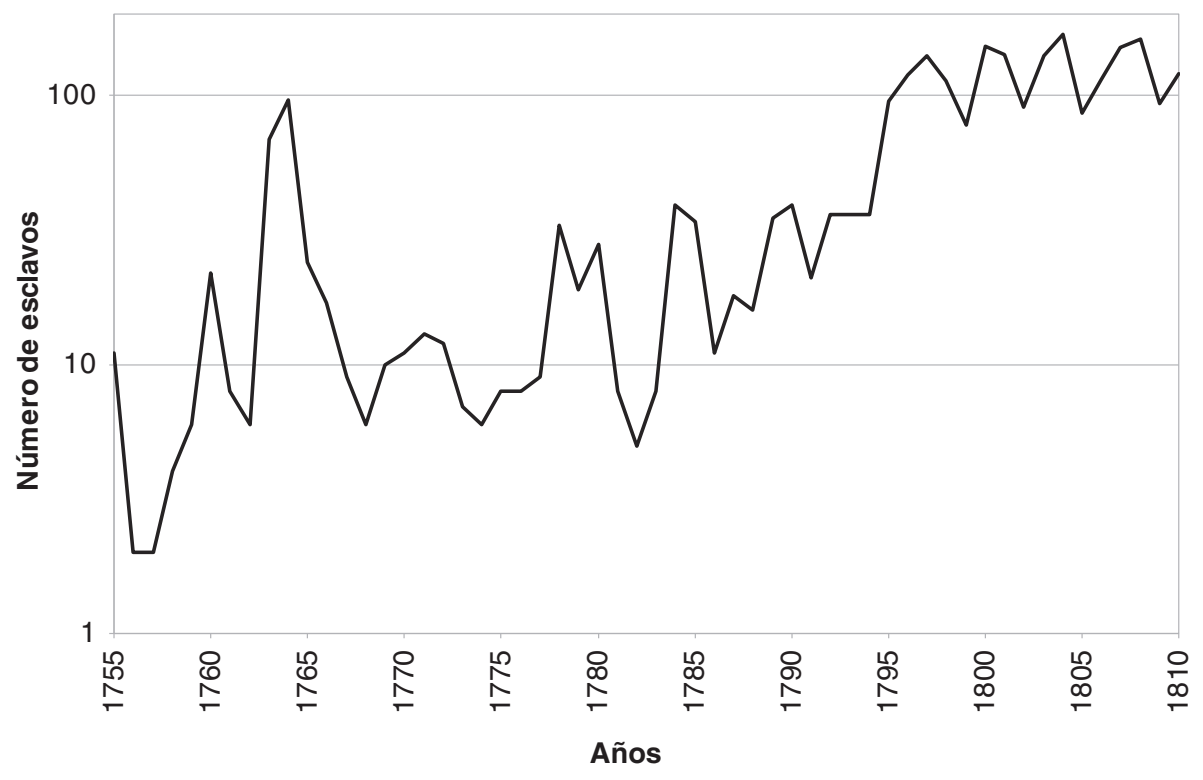

— Migración forzada

Fuente: elaboración propia a partir de los libros de bautismos y entierros de la iglesia parroquial de San Carlos de Matanzas.

El tránsito por la coyuntura, el crecimiento y la estabilización del flujo migratorio es una muestra clara del proceso de transformación de las relaciones de trabajo en Matanzas ha- 
cia la intensificación del mercado de trabajo esclavo. Parece claro que el apoyo institucional al proyecto económico de las élites tuvo un efecto positivo en la estabilización de la entrada masiva de mano de obra esclava, lo que facilitó el camino hacia la consolidación del nuevo modelo social y económico. Sin embargo, el crecimiento de la fuerza de trabajo negra no solo se dio gracias al aumento de las importaciones forzadas de población africana.

El crecimiento neto de la población negra del Gráfico 5 muestra que la evolución de la disponibilidad de fuerza de trabajo fue cercana a cero antes de 1783. Esto se produjo debido a que la inmigración forzada, aún muy reducida (cerca de diez esclavos al año), no conseguía más que compensar el crecimiento natural negativo. A partir de 1783 el crecimiento es siempre positivo y tiende a crecer en términos absolutos. En los primeros años y hasta 1794 este crecimiento procede a partes relativamente iguales del crecimiento natural, que entre 1783 y 1794, como se ha visto, fue positivo, y del aumento regular de la inmigración forzada. La principal característica de este periodo de transformación fue la combinación de nacimientos e importaciones.

\section{GRÁFICO 5}

Evolución de las entradas (nacimientos e inmigración), defunciones y crecimiento neto de la población negra en Matanzas, 1755-1810

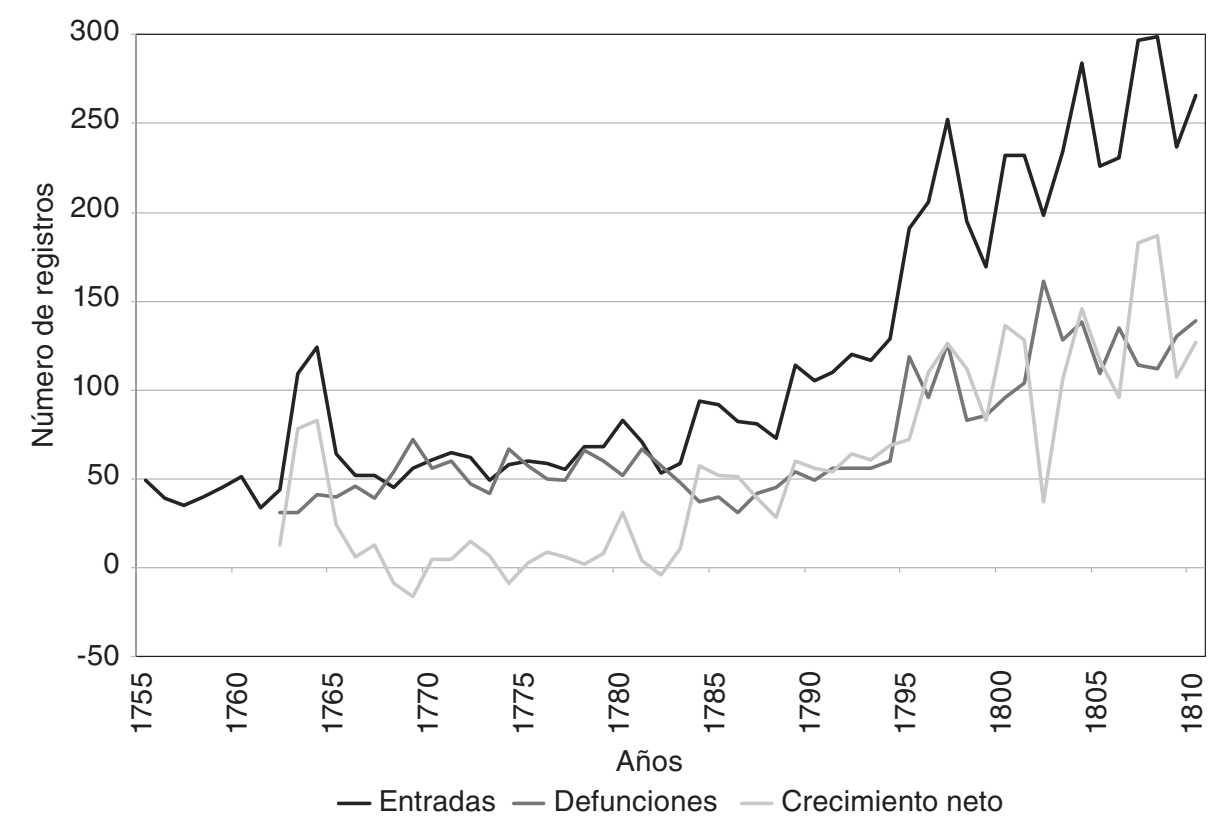

Fuente: elaboración propia a partir de los libros de bautismos y entierros de la iglesia parroquial de San Carlos de Matanzas. 
A partir de 1794 y hasta 1810 el crecimiento anual de la población se mantiene en valores más altos, aunque muy fluctuantes (alrededor de los 120 efectivos nuevos por año). En este periodo el factor que contribuye al crecimiento de la población negra es la inmigración forzada, ya que el crecimiento natural mantiene valores muy bajos e incluso negativos hasta 1805 . En esta etapa de consolidación de la nueva sociedad, la inmigración forzada tuvo un papel fundamental.

¿Qué jugó a favor o en contra de las garantías a la reproducción de la población negra? ¿Por qué el crecimiento natural fue positivo durante la etapa de transformaciones y volvió a caer cuando las entradas de inmigrantes forzados se hicieron masivas? Entre los factores que influyen sobre la natalidad queremos resaltar dos: a) los cambios en la proporción que representaban las mujeres; y b) las dificultades de reproducción de una población en la que la relación entre los libres y los esclavos era cada vez menor.

TABLA 2

Relación de masculinidad de la población esclava importada y bautizada en Matanzas, 1755-1769/1780-1799

\begin{tabular}{lccc}
\hline Años & Hombres & Mujeres & Ratio H/M \\
\hline $1755-1759$ & 21 & 3 & 700 \\
$1760-1764$ & 126 & 67 & 188 \\
$1765-1769$ & 51 & 10 & 510 \\
$1780-1784$ & 64 & 17 & 376 \\
$1785-1789$ & 69 & 31 & 223 \\
$1790-1794$ & 107 & 37 & 289 \\
$1795-1799$ & 444 & 66 & 673 \\
\hline Totales & $\mathbf{8 8 2}$ & $\mathbf{2 3 1}$ & $\mathbf{3 8 2}$ \\
\hline
\end{tabular}

Fuente: elaboración propia a partir de los libros de bautismos y entierros de la iglesia parroquial de San Carlos de Matanzas.

El incremento de las importaciones de esclavos no solo modificó los efectivos totales de la población, sino también su composición. Analizando los censos se ha resaltado que la importación masiva de esclavos fue principalmente masculina al inicio del proceso de crecimiento y que la proporción de esclavos aumentó en detrimento de la población libre (Tornero, 1996: 115-130; Moreno, 2001 [1964]: 330-333). El uso de registros parroquiales ha permitido evaluar la evolución de las proporciones de hombres y mujeres en las importaciones de esclavos para el periodo de formación del sistema esclavista (Tabla 2), y en un futuro sería interesante explorar también la relación entre libres y esclavos como otro de los determinantes del crecimiento natural de la población negra. 
La evolución de la relación de masculinidad de las importaciones de esclavos entre 1755-1799 confirma la idea general de la «masculinización» de la fuerza de trabajo esclava africana. A pesar de ello, esta proporción no es homogénea a lo largo de todo el periodo de cambio y se distinguen tres etapas.

En la primera ola de entradas de 1763-1764 no hay una diferencia muy grande entre la cantidad de mujeres y hombres, y la relación de masculinidad de 1760-1764 es la más baja del periodo. En las importaciones de 1780 a 1794 la entrada de mujeres es minoritaria, pero no insignificante. Por cada mujer hay de dos a cuatro hombres. En este periodo las mujeres representan entre el $21 \%$ y el $43 \%$ de las importaciones, y llegan incluso al $73 \%$ en 1786 . Finalmente, entre $1795-1799$, durante la segunda gran oleada de importación de esclavos, la proporción de mujeres cayó drásticamente. Por cada mujer hay unos siete hombres, y en términos relativos las importaciones de mujeres se sitúan en torno al $15 \%$ de la importación total de esclavos y alcanzan su punto más bajo en 1797 con un $8 \%$.

Los datos disponibles muestran que la escasa presencia de mujeres durante el periodo inicial de la expansión azucarera ha de ser matizada. Los altos valores de la relación de masculinidad se producen en el periodo previo al cambio y durante su intensificación. Durante la etapa de transición la caída de la relación de masculinidad y el aumento de la proporción de mujeres coincide temporalmente con los valores positivos del crecimiento natural (Gráfico 5).

Las importaciones y el crecimiento natural entre 1785-1795 fueron vías complementarias para garantizar el aumento de la fuerza de trabajo negra debido a que se importaron más mujeres que en cualquier otro periodo. Sin embargo, la consolidación del sistema de plantación después de esta fecha llevó a que predominara la importación de mano de obra esclava masculina. Este cambio en la naturaleza de las importaciones habría causado restricciones al crecimiento natural de la población negra en su conjunto. Un crecimiento volátil y dependiente de las importaciones de esclavos hombres es otra de las características de la implantación del nuevo sistema productivo en el periodo posterior.

La dependencia del sistema de plantación de las importaciones de esclavos en las plantaciones del Caribe y en Cuba no es un hecho novedoso. No obstante, se apunta como novedad que durante la transformación hacia el sistema de plantación esclavista en Matanzas (1785-1795), el crecimiento total de la fuerza de trabajo negra fue posible gracias a la combinación del crecimiento natural y el aumento progresivo de las importaciones de esclavos de ambos sexos. La dependencia de las importaciones fue un fenómeno posterior. Hubo un momento intermedio en el que se guardaron las proporciones entre hom- 
bres y mujeres, aunque más por las limitaciones institucionales a la trata y el desarrollo de la economía azucarera, como se ha mostrado más arriba, que por voluntad ética de los plantadores.

\subsection{La demanda: crecimiento horizontal y vertical de los propietarios}

Garantizar la disponibilidad de fuerza de trabajo fue uno de los principales objetivos de la élite plantadora. Hemos visto que esto se consiguió gracias al crecimiento natural y la inmigración forzada durante la etapa de transición y a las importaciones intensivas durante la consolidación del sistema de plantación, pero ¿cuál fue el comportamiento desde el lado de la demanda? ¿Qué caracterizó el aumento de la capacidad de absorción de la mano de obra esclava? Este comportamiento será analizado a partir de la evolución del número de propietarios, del tamaño de las explotaciones y del avance espacial del proceso ${ }^{8}$.

En el Gráfico 6 se observa la serie anual del número de propietarios y la serie de las entradas de esclavos (por nacimiento e inmigración). No hay datos entre 1770-1780, pero los valores de aquellos dos años difieren poco, así que se ha supuesto una relativa estabilidad del número de propietarios en torno a los 15-20 efectivos para el periodo, similar a la década de los años de 1760 . Si tenemos en cuenta que no fue un periodo de crecimiento de la población negra (Gráfico 3), muy difícilmente pudo haber aumentado la cantidad de propietarios de esclavos.

Esto no quiere decir que haya sido un periodo de estancamiento. Como ya se ha destacado, durante estos años las élites locales mostraron su interés por el desarrollo de la actividad azucarera en Matanzas. Las reclamaciones que se observan en sus análisis y discursos sobre el desarrollo económico de la isla coinciden con el interés de la corona de revivir su proyecto reformista y sus fines político-militares tras el fin de la guerra de los Siete Años. Este es el momento en el que la familia del marqués de Justis de Santa Anna y el conde de Gibacoa pasan del tabaco al azúcar (Bergad, 1990: 12-13), y cuando se escriben los principales discursos sobre el aumento de la producción agraria y la falta de brazos.

El periodo 1780-1795 nuevamente aparece como un periodo de cambio de tendencia y ruptura. En esta etapa el crecimiento del número de propietarios es significativo y es la contraparte de la disponibilidad creciente de población esclava. Finalmente, el nú-

8. En este apartado se ha excluido a toda la población libre; por este motivo se habla de mano de obra esclava y no de fuerza de trabajo negra. 
mero de propietarios parece estabilizarse en torno a los setenta efectivos a partir de 1795; no obstante, este fenómeno observado en este momento no es extrapolable por continuidad a las primeras décadas del siglo xIX, cuando tuvo lugar el auge del azúcar.

\section{GRÁFICO 6}

Series anuales de entradas de esclavos (nacidos e inmigrantes) y del número de propietarios, 1755-1799

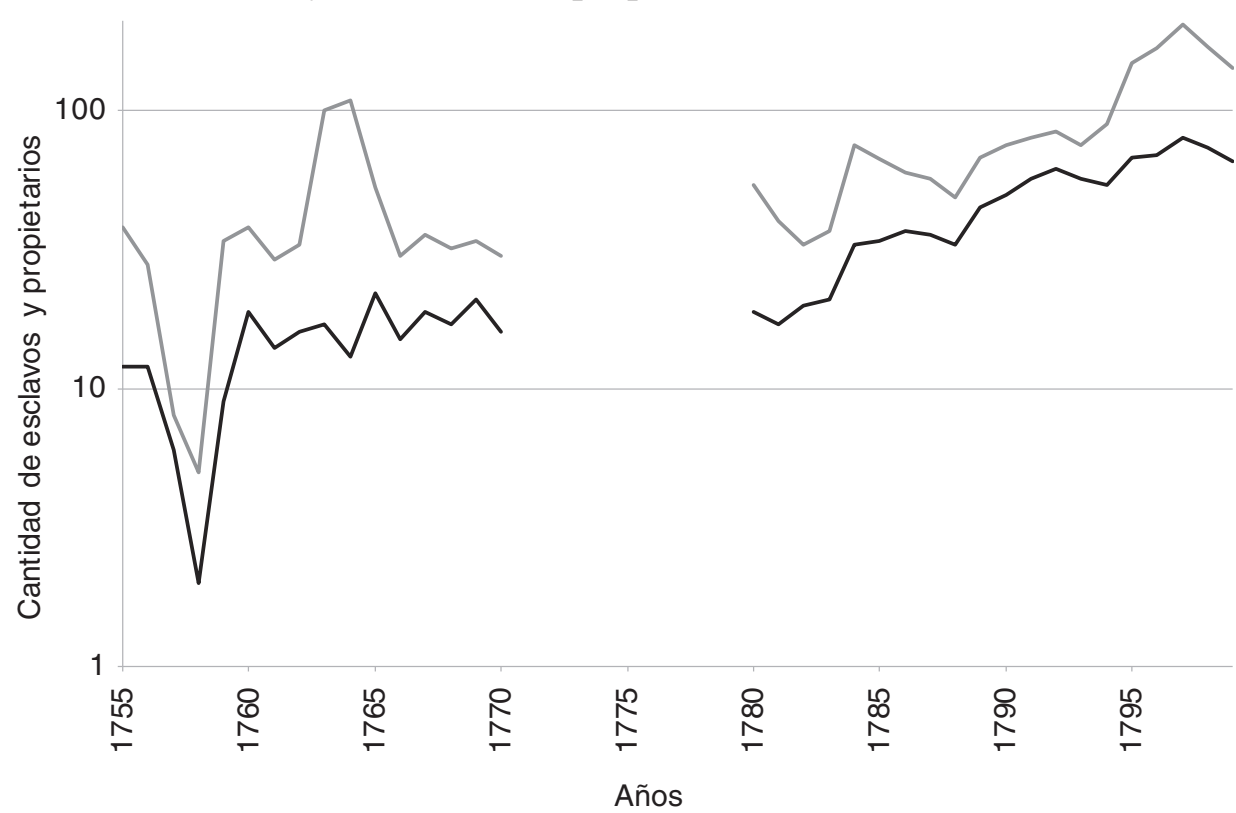

- Propietarios — Esclavos

Nota: la cantidad de esclavos corresponde al número de menciones de esclavos (importados y nacidos) en la muestra de 2.415 registros con nombres de propietarios y no a las importaciones del Gráfico $2 \mathrm{o}$ a los nacimientos del Gráfico 3.

Fuente: elaboración propia a partir de los libros de bautismos y entierros de la iglesia parroquial de San Carlos de Matanzas.

El aumento cuantitativo y la estabilización del número de propietarios dieron forma al corazón de una nueva clase social con poder económico y que consiguió el soporte de las instituciones reales. La capacidad de presión de este grupo debió ser fundamental para la consecución de los beneficios que obtuvo la agricultura de plantación. R. Funes (2008: 2, 41-43) señala las tensiones por el uso de bosques para la construcción de barcos o la producción de azúcar entre la corona y los plantadores, resuelta a favor de los últimos. Una vez aseguradas las garantías institucionales para su proyecto económico la estabilización del número de propietarios podría leerse como un paso hacia la restricción de los canales de acceso y la consolidación de la nueva clase. 
¿Están relacionados con la producción de azúcar estos propietarios? Para este periodo, los datos no permiten hacer afirmaciones tajantes. El declive del tabaco empezó en la década de 1760, pero esto no significó su desaparición. Por otro lado, no se debe olvidar que el aumento de la producción de azúcar solo fue posible gracias a la introducción de más unidades de trabajo y la ampliación de la frontera agrícola, y que fue el trabajo y no la tierra el factor escaso.

La relevancia de la mano de obra esclava en el desarrollo de la economía de plantación azucarera se evidencia si tomamos las exportaciones anuales de azúcar de Cuba como indicador del desarrollo de la economía de plantación entre 1777-1810 (Moreno, 2001 [1964]) y las comparamos con el número de esclavos bautizados en Matanzas en el mismo periodo. El resultado es una correlación positiva $(0,79)$ entre las dos variables. Esto no quiere decir que no se usaran esclavos en actividades diferentes a las de la plantación azucarera, pero sí dice que los esclavos estuvieron estrechamente vinculados a la producción de azúcar, quizá más que al tabaco si se tiene en cuenta que este cultivo se caracterizó por su vínculo con la agricultura familiar (Bergad, 1990: 9-10).

Hasta ahora se ha mostrado que existió un incremento del número de propietarios de esclavos y que los esclavos fueron destinados principalmente a la producción de azúcar, pero no queda claro cuál fue el comportamiento del tamaño de las explotaciones agrarias a lo largo del proceso de trasformación, ni cómo y cuándo adquirió la gran explotación su protagonismo. Para despejar estas dudas, se ha asumido que cuanto más alto fuera el número de esclavos en relación con el de propietarios, más facilidades habría habido para que el tamaño de las explotaciones aumentara.

Al cruzar la cantidad de esclavos por familia o propietario entre 1790-1799 con la cantidad de tierra poseída en el registro de propietarios del corral de Matanzas en 1801 se obtuvo una positiva y fuerte correlación $(0,94)^{9}$; es decir, que los mayores propietarios de tierras en el partido de Matanzas también fueron grandes propietarios de esclavos. Este resultado valida el número de esclavos como indicador aproximado del tamaño de las explotaciones. Así, para observar la evolución del tamaño, se utiliza el número medio de esclavos por propietarios y se distribuye por cantidad de esclavos bautizados para observar la dinámica de los grupos de propietarios por tamaños. Además, se distribuyen 26 propietarios de tierras del mapa de propietarios del corral de Matanzas de 1801 según el número de esclavos poseídos entre 1790-1799 con el objetivo de comparar el avance espacial del proceso en el corral de Matanzas con respecto al resto de la región.

9. Mapa de propietarios de caballerías en el corral de Matanzas en 1801. Archivo General de Indias, MP-SANTO_DOMINGO, 623. 


\section{TABLA 3}

Cantidad media de esclavos bautizados por propietario y desviación estándar para las décadas de 1760, 1780 y 1790

\begin{tabular}{lcccc}
\hline Años & Esclavos (a) & Propietarios (b) & a/b & Desviación estándar $^{*}$ \\
\hline $1760-1769$ & 494 & 91 & 5,4 & 20 \\
$1780-1789$ & 540 & 148 & 3,6 & 11 \\
$1790-1799$ & 1.238 & 288 & 4,3 & 10 \\
\hline
\end{tabular}

* La desviación estándar corresponde a la dispersión del número de esclavos entre la cantidad de propietarios para cada década.

Fuente: elaboración propia a partir de los libros de bautismos y entierros de la iglesia parroquial de San Carlos de Matanzas.

La evolución del tamaño medio muestra que en 1760-1769 y 1790-1799 las posibilidades para aumentar el tamaño de las explotaciones agrarias fueron más altas que en 17801789 y se evidencia una caída significativa de la dispersión. Esto indica que hubo una reducción de las diferencias entre grandes y pequeñas explotaciones (Tabla 3). Con base en la estabilidad del número de propietarios durante la década de 1760 (Gráfico 6) se puede deducir que la repentina entrada de población esclava en 1763-1764 sirvió para suplir las necesidades de mano de obra de los propietarios existentes, lo que permitió el aumento del tamaño de sus explotaciones. No obstante, la amplia dispersión entre los valores extremos sugiere que esto solo habría sido posible para algunos grandes propietarios, como Gerónimo Contreras y el marqués Justis de Santa Anna, que bautizaron 170 y 82 esclavos, respectivamente, coincidiendo con el giro hacia el azúcar de estas dos grandes familias y que ha sido señalado más arriba.

En contraste, en la década de 1780, mientras la tendencia del número de esclavos iba en aumento, el tamaño medio de las explotaciones descendió. Al parecer la proliferación del número de propietarios fue mucho más rápida que los nacimientos e importaciones de esclavos (Tabla 3). Finalmente, la intensidad del crecimiento del número de propietarios se estabilizó y el incremento del número de esclavos no solo alimentó más explotaciones, sino que además sirvió para aumentar su tamaño al final del periodo (Tabla 3). Este crecimiento vertical de la demanda es la otra cara de las importaciones masivas de esclavos (Gráfico 4).

Las posibilidades para el desarrollo de grandes explotaciones fueron altas en el primer y el último periodo, pero la consolidación de la unidad productiva que tomó fuerza durante la década de 1790 no tiene nada que ver, en tamaño, con la forma de la de 1760 y quizá tampoco con los ingenios del siglo XIX. Aunque el aumento de las explotaciones no haya sido relevante para el periodo intermedio (1780-1789), la desviación estándar, que cae a la mitad, indica que las explotaciones de tamaño medio habrían empezado a 
ganar terreno en este momento. Esta idea sitúa al mediano propietario de esclavos como un agente relevante en las transformaciones hacia el azúcar.

La agrupación de los propietarios en pequeños, medianos y grandes permite observar el comportamiento de los medianos propietarios en relación con los otros grupos. Se consideraron pequeños propietarios aquellos que tenían entre 1 y 5 esclavos, medianos a los que poseían entre 6 y 20 , y grandes a partir de 21 . Se hicieron tres cortes temporales y se calculó la tasa de crecimiento anual de cada grupo para ver su dinamismo entre los periodos.

Los propietarios con menos de cinco esclavos fueron el grupo mayoritario a lo largo de todo el periodo, pero su evolución revela un contraste interesante. La caída de la representatividad entre los propietarios con 1-3 esclavos frente al aumento de los de 4-5 esclavos (Tabla 4). La relevancia de estos últimos es tal que en términos de crecimiento anual fue el grupo más dinámico del primer periodo. La distinción entre estos dos grupos posiblemente marca el uso de esclavos en el servicio doméstico y pequeñas explotaciones agrarias. Sin embargo, se carece de información suficiente para hacer una afirmación tajante al respecto.

Entre los grupos que claramente están vinculados a la explotación agraria de plantación encontramos a medianos y grandes propietarios de esclavos. Estos representaron alrededor de un $11 \%-12 \%$ del total de los propietarios, excepto durante la época de las transformaciones, cuando cayó su representatividad al 6\%. Solo los propietarios medianos con 11-20 esclavos crecieron entre 1760-1789, pero a partir de 1790 el crecimiento se concentró entre estos grupos (Tabla 4). La reducción de la dispersión de la distribución entre 1760-1789 (Tabla 3) se produjo por el aumento de los propietarios con 4-5 y 11-20 esclavos, y el poco dinamismo de los propietarios con 1-3 y más de 21 esclavos. Entre 1789-1799 esta dispersión se mantuvo al mismo nivel gracias a que los medianos propietarios crecieron al mismo ritmo que los grandes, lo que redujo las diferencias entre ambos.

Una idea que subyace en este proceso es el crecimiento del tamaño de las explotaciones a medida que se fue ampliando el acceso a la mano de obra esclava. La creciente disponibilidad de esclavos en la década de 1780 habría permitido el nacimiento de pequeños propietarios y el salto de algunos hacia la media explotación; durante la década siguiente, el paso hacia la media y gran explotación estaría vinculado a la entrada masiva de mano de obra esclava. El primer fenómeno explica la proliferación de propietarios (Gráfico 6) y el segundo el aumento del tamaño de las explotaciones en la década de 1780 (Tabla 3). No obstante, no se puede olvidar que el verdadero protagonismo de la plan- 
tación habría que ubicarlo a partir de 1795, época en que coinciden el inicio de las importaciones masivas (Gráfico 4) y la estabilización del número de propietarios (Gráfico 6). La idea de un progresivo crecimiento vertical de la demanda vendría reforzada por la disminución de la dispersión y el aumento del tamaño de las explotaciones al final del periodo (Tabla 3).

TABLA 4

Distribución de los propietarios por número de esclavos entre 1760-1799 y tasas de crecimiento anual

\begin{tabular}{lrrrrrrrr}
\hline Grupos de & \multicolumn{2}{c}{$\mathbf{1 7 6 0 - 1 7 6 9}$} & \multicolumn{2}{c}{$\mathbf{1 7 8 0 - 1 7 8 9}$} & \multicolumn{2}{c}{$\mathbf{1 7 9 0 - 1 7 9 9}$} & \multicolumn{2}{c}{ Crecimiento acumulado anual } \\
propietarios & NE & $\%$ & NE & $\%$ & NE & $\%$ & $\mathbf{1 7 6 9 - 1 7 8 9}$ & $\mathbf{1 7 8 9 - 1 7 9 9}$ \\
\hline$[1-3]$ & 77 & 84,6 & 118 & 79,7 & 217 & 75,3 & $2 \%$ & $6 \%$ \\
{$[4-5]$} & 4 & 4,4 & 19 & 12,8 & 36 & 12,5 & $8 \%$ & $7 \%$ \\
{$[6-10]$} & 5 & 5,5 & 5 & 3,4 & 16 & 5,6 & $0 \%$ & $12 \%$ \\
{$[11-20]$} & 1 & 1,1 & 3 & 2,0 & 8 & 2,8 & $6 \%$ & $10 \%$ \\
{$[21-40]$} & 2 & 2,2 & 1 & 0,7 & 5 & 1,7 & $-3 \%$ & $17 \%$ \\
{$[>40]$} & 2 & 2,2 & 2 & 1,4 & 6 & 2,1 & $0 \%$ & $12 \%$ \\
& 91 & 100 & 148 & 100 & 288 & 100 & $2 \%$ & $7 \%$ \\
\hline
\end{tabular}

Nota: $\mathrm{NE}=$ número de esclavos.

Fuente: elaboración propia a partir de los libros de bautismos y entierros de la iglesia parroquial de San Carlos de Matanzas.

En el plano sociopolítico este crecimiento (horizontal y vertical) de una nueva clase social con un poder económico en aumento lleva a pensar que los propietarios con explotaciones pequeñas y medias, seducidos por los beneficios económicos del azúcar, podrían haber sido la "masa» que hizo posible el aumento de la presión política sobre las instituciones coloniales y que, orquestada por los grandes propietarios, habría conseguido las transformaciones institucionales necesarias para garantizar el desarrollo de la plantación y la llegada de más esclavos.

Aunque en este artículo se ha querido dar protagonismo a los grupos intermedios para llamar la atención sobre el nacimiento de los plantadores como nueva clase social, los grandes propietarios son muy relevantes. Si los pequeños y medianos propietarios fueron los protagonistas durante el periodo de transformación, los grandes propietarios lo fueron en el periodo inicial y durante la consolidación del sistema de plantación.

La representatividad de los grandes propietarios ( $>21$ esclavos) en el conjunto de propietarios siempre fue baja, entre el $4,4 \%$ y el $2 \%$, pero en sus manos se concentró la mayor cantidad de esclavos usados en las plantaciones. Más del $60 \%$ de la fuerza de trabajo 
esclava de 1760-1769 estaba en sus manos. Aunque entre 1780-1789 se produjo una redistribución de los esclavos en favor de los pequeños y medianos propietarios (Tabla 4), en el momento de crecimiento de la plantación se produjo una reconcentración de la mano de obra esclava, y los grandes propietarios lograron recuperar el control sobre más del $40 \%$ de los esclavos disponibles.

Si observamos solo al $10 \%$ de los mayores propietarios de cada corte temporal (incluidos los medianos y grandes propietarios para 1760 y 1780), la evolución del proceso de concentración es importante. Más de la mitad de la mano de obra esclava disponible en todos los periodos estuvo en manos de un pequeño grupo de personas. Sin embargo, la tendencia de largo plazo es decreciente: del $72 \%$ en 1760 pasó al $50 \%$ en 1799 .

La redistribución y la concentración de la fuerza de trabajo esclava fueron las dos características, desde la demanda, de la transformación e implantación del nuevo sistema. La primera se produjo de forma mucho más importante en la década de 1780 a causa de la proliferación de propietarios con pequeñas y medianas explotaciones. La segunda corresponde al periodo siguiente y se dio gracias al crecimiento de las explotaciones, especialmente dentro de los grupos intermedios.

Finalmente, con los datos del mapa de propietarios de Matanzas de 1801 se compara el desarrollo de la concentración de esclavos entre el área más cercana al núcleo de población, el corral de Matanzas, y la región en general. De 43 propietarios de tierras se usaron 26 , que se corresponden con los nombres de propietarios de esclavos en los registros parroquiales.

La distribución de la tierra entre propietarios muestra un marcado desequilibrio. Mientras el marqués Justis de Santa Anna, el conde de Gibacoa y el rey poseían entre 1.200 y 9.600 hectáreas, el tamaño medio de las otras propiedades era de unas cien hectáreas ${ }^{10}$. Además, estos tres propietarios también figuran entre los diez principales propietarios de esclavos de la región en 1790-1799. Los 23 propietarios restantes podrían ser asociados a esclavistas de tamaño medio con 6-20 esclavos.

El análisis comparativo entre la distribución del número de esclavos de estos 26 propietarios del corral de Matanzas (Tabla 5) y la del conjunto de propietarios de la región

10. Para las conversiones se usaron las siguientes equivalencias: 1 caballería $=324$ cordeles cuadrados; 1 caballería $=0,39 \mathrm{~km}^{2} ;$ y $1 \mathrm{~km}^{2}=100$ hectáreas. Consultado en: http://www.convertme.com/es/convert/history_area/escaballeria.html http://www-personal.umich.edu/ dfrye/fanega.htm 
en 1790-1799 (Tabla 4) muestra diferencias interesantes. El peso de los pequeños propietarios con 1-3 esclavos en el corral de Matanzas es marcadamente menor, del 35\% frente al $75 \%$. Los propietarios que por su tamaño han sido claramente vinculados con el uso de esclavos en explotaciones agrarias (medianos y grandes) representan casi la mitad del total de los propietarios, mientras que para la región completa no llegan al $12 \%$. Además, el peso de los grandes propietarios (> 21 esclavos) en el corral de Matanzas llega al $15 \%$, muy por encima del resto de la región, donde apenas alcanza el $4 \%$.

\section{TABLA 5}

Distribución de los propietarios de tierras del mapa del corral de Matanzas de 1801 por tamaño según la cantidad de esclavos, 1790-1799

\begin{tabular}{lrr}
\hline Grupos de propietarios & NE & $\%$ \\
\hline$[1-3]$ & 9 & 34,6 \\
{$[4-5]$} & 5 & 19,2 \\
{$[6-10]$} & 4 & 15,4 \\
{$[11-20]$} & 4 & 15,4 \\
{$[21-40]$} & 1 & 3,8 \\
{$[>40]$} & 3 & 11,5 \\
& 26 & 100 \\
\hline
\end{tabular}

Nota: NE = número de esclavos.

Fuente: elaboración propia a partir de los libros de bautismos y entierros de la iglesia parroquial de San Carlos de Matanzas. Mapa de propietarios de caballerías en el corral de Matanzas en 1801. Archivo General de Indias, MP-SANTO_DOMINGO, 623.

El corral de Matanzas parece una punta de lanza de las transformaciones que trajo consigo la consolidación del sistema de plantación, es decir, el aumento del peso de medianos y grandes propietarios. El proceso que se apunta con los datos del corral parece mucho más maduro que el que se describe para el resto de la región en el mismo periodo (1790-1799). Posiblemente esta intensidad del corral de Matanzas refleje la dirección de los cambios que sufrió el resto de la provincia años más tarde. La facilidad del acceso a vías fluviales, el puerto y la condición de primer núcleo de población son elementos importantes a la hora de marcar este avance espacial del proceso.

\section{CONCLUSIONES}

El análisis empírico del mercado de trabajo esclavo en Matanzas confirma el proceso de cambio hacia la sociedad esclavista que tuvo lugar en Cuba a partir de la segunda mitad del siglo XVIII. Esta transformación fue posible gracias al soporte de las instituciones reales. La corona apoyó el proyecto económico de las élites locales introduciendo regulaciones 
favorables al desarrollo del sistema de plantación, como la liberalización del mercado de tierras, la producción y comercialización de productos de plantación y el acceso a mano de obra esclava.

El crecimiento del tamaño de las explotaciones agrarias esclavistas y la política de introducción masiva de esclavos masculinos de finales de la década de 1790 son una muestra de la consolidación del nuevo pacto colonial. Si bien el marco institucional inicial no impedía la esclavitud, no fue hasta finales del siglo XvIII cuando se produjo la intensificación de las relaciones que favorecieron el desarrollo de la sociedad esclavista y la economía de plantación. Esto fue posible gracias a la confluencia de intereses entre las élites locales y la corona. El azúcar ofrecía rentas a las primeras a cambio de lealtad y estabilidad política para la segunda.

En términos generales el artículo confirma el conocimiento previo sobre la evolución del crecimiento de la población negra y la intensificación de la agricultura de plantación que la historiografía ha referido a partir de 1790, pero además aporta nuevos datos para una región relevante y un periodo poco estudiado. Esta información permite cuestionar algunos planteamientos de la New Institutional Economics sobre la formación temprana de la sociedad esclavista en Cuba, o al menos matizar el momento de su intensificación.

En concreto se ha logrado establecer una periodización precisa del cambio institucional en Matanzas identificando un punto de inflexión y una diferencia clara entre un periodo de transformaciones y uno de implantación definitiva del sistema de plantación esclavista. El punto de ruptura hacia el nuevo sistema se ha podido situar entre 17801785. A partir de este momento se ha caracterizado una etapa de transición, marcada por un contexto internacional favorable. Después de 1795 una etapa de estabilización y consolidación del nuevo sistema, que refleja la madurez del pacto entre las élites locales y la corona.

Las principales características del periodo de transición (1785-1795) son:

a) El aumento de la disponibilidad de la fuerza de trabajo negra gracias a la combinación del crecimiento natural y el aumento progresivo de las importaciones de esclavos. Las limitaciones institucionales impuestas a la trata negrera y la necesidad de mano de obra favorecieron cierta proporción sexual en las importaciones de esclavos garantizando así este escenario.

b) El crecimiento horizontal de la demanda. En este periodo tuvo lugar una proliferación de pequeños y medianos propietarios y una redistribución de la fuerza 
de trabajo esclava. El nacimiento de esta nueva clase social coincide con la introducción progresiva de reformas favorables al proyecto esclavista.

Las principales características del periodo de estabilización (1795-1810) son:

a) La volatilidad en la disponibilidad de la fuerza de trabajo negra, marcada por la dependencia de importaciones masivas de mano de obra esclava masculina y el fin de las garantías a la reproducción de la población negra.

b) El predominio del crecimiento vertical de la demanda. Este proceso dio inicio a una nueva etapa de concentración de esclavos en manos de medianos y grandes propietarios, lo que facilitó el aumento de las explotaciones esclavistas.

Para este periodo de estabilización y consolidación se ha podido observar que la intensificación de la explotación esclavista se dirigió desde el corral de Matanzas hacia el interior de la provincia, anunciando el camino de los cambios que se producirán en el resto de la región en las décadas posteriores.

Finalmente, se ha puesto de manifiesto la utilidad de los registros parroquiales para la historia económica más allá del análisis que ofrece la demografía histórica o el enfoque biográfico de la nueva historia cultural. Se ha abordado la información necesaria para estudiar las transformaciones en el mercado de trabajo esclavo, pero las posibilidades de la fuente no se agotan aquí. Un trabajo más ambicioso podría explorar la posibilidad de aplicar el análisis propuesto para el resto de las parroquias de la isla con el objetivo de establecer contrastes y cronologías más detalladas sobre la evolución e impacto regional del cambio hacia el azúcar antes del siglo XIX en Cuba.

\section{AGRADECIMIENTOS}

Este trabajo se inscribe en el proyecto HAR2015-69620-C2-1-P, financiado por el MINECO. Agradezco a Roser Nicolau Nos y Anna Carreras Marín por sus sugerencias y comentarios durante el planteamiento y elaboración de la primera versión del artículo. También a Jordi Planas Maresma y los dos evaluadores anónimos que contribuyeron con sus revisiones a mejorar la versión enviada a la revista. 


\section{REFERENCIAS}

Acemoglu, D., Johnson, S. \& Robinson, J. A. (2001). The Colonial Origins of Comparative Development: An Empirical Investigation. The American Economic Review, 91 (5), 1369-1401.

Arteaga, F. (2017). Fragmentation of an Empire: The Political Economy of Spain and its Colonies in the Late Bourbon Period. IV Seminario «Nuevos historiadores económicos de Latinoamérica». Madrid, 20 de enero.

BeLmonte, J. L. (2010). «Brazos para el azúcar», esclavos para vender: Estrategias de comercialización en la trata negrera en Santiago de Cuba, 1789-1794. Revista de Indias, 70 (249), 445-468.

Belmonte, J. L. (2014). Las dos caras de una misma moneda: Reformismo y esclavitud en Santo Domingo a fines del periodo colonial. Revista de Indias, 74 (261), 453-482. Bergad, L. W. (1987). Slave Prices in Cuba, 1840-1875. The Hispanic American Historical Review, 67 (4), 631-655.

Bergad, L. W. (1990). Cuban Rural Society in the Nineteenth Century: The Social and Economic History of Monoculture in Matanzas. Princeton: Princeton University Press.

Bergad, L.W. (2007). The Comparative Histories of Slavery in Brazil, Cuba, and the United States. New York: Cambridge University Press.

Bergad, L.W., García, F. \& BARCIA, M. C. (1995). The Cuban Slave Market, 1790-1880. Cambridge: Cambridge University Press.

Chaviano, L. J. (2013). Trinidad, una historia económica basada en el azúcar, 1765-1848. Tesis doctoral. Barcelona: Universitat Pompeu Fabra.

Curtin, P. D. (1969). The Atlantic Slave Trade: A Census. Madison: University of Wisconsin Press.

Eblen, J. E. (1975). On the Natural Increase of Slave Population: The Example of the Cuban Black Population, 1775-1900. In S. L. ENGERMAN \& E. D. Genovese, Race and Slavery in the Western Hemisphere: Quantitative Studies (pp. 211-248). Stanford: Center for Advanced Study in the Behavioral Sciences.

ELtis, D. (1987). Economic Growth and the Ending of the Transatlantic Slave Trade. New York: Oxford University Press.

Eltis, D. (Ed.) (2010). The Trans-Atlantic Slave Trade Database. http://www.slavevoyages.org/

Eltis, D., Lewis, F. D. \& RichaRdson, D. (2005). Slave Prices, the African Slave Trade, and Productivity in the Caribbean, 1674-1807. The Economic History Review, 58 (4), 673-700.

Eltis, D., Lewis, F. D. \& Sokoloff, K. L. (2004). Slavery in the Development of the Americas. Cambridge: Cambridge University Press. 
EsPinosa, L. M. \& BeldarRaín, E. (2005). Cuba y México: Desastres, alimentación y salud: Siglos XVIII-XIX: Estudios de caso. México, DF: Plaza y Valdés.

FunEs, R. (2008). From Rainforest to Cane Field in Cuba:An Environmental History since 1492. Chapel Hill: University of North Carolina Press.

García Álvarez, A. \& SANTAMaría, A. (2004). El azúcar y la historiografía cubana. En A. VIEIRA (Coord.), O açucar e o quotidiano: Actas do congresso internacional sobre a Historia do Açúcar (pp. 489-528). Funchal: Centro de Estudos de História do Atlántico.

GARCía RodrígueZ, M. (2006). Ingenios habaneros del siglo XVIII: Mundo agrario interior. América Latina en la historia económica, 13 (2), 41-75.

Gomes, F. (2012). A demografia atlântica dos africanos no Rio de Janeiro, séculos XVII, XVIII e XIX: Algumas configuraçoes a partir dos registros eclesiásticos. História, Ciências, Saúde-Manguinhos, 19 (1), 81-106.

KuEIN, H. S. (1986). African Slavery in Latin America and Caribean. New York: Oxford University Press.

Lucena, M. (1996). Los códigos negros de la América española. Alcalá de Henares: UNESCO/Universidad de Alcalá de Henares.

MARrero, L. (1984). Cuba: Economía y sociedad: Azúcar, ilustración y conciencia. Madrid: Playor.

Meriño, M. A. \& Perera, A. (2006). Esclavitud, familia y parroquia en Cuba: Otra mirada desde la microhistoria. Revista Mexicana de Sociología, 68 (1), 137-180.

Meriño, M. A. \& Perera, A. (2008). Esclavitud, familia y parroquia en Cuba. Santiago de Cuba: Oriente.

Moreno, M. (2001 [1964]). El ingenio: Complejo económico social cubano del azúcar. Barcelona: Crítica.

North, D. C., Wallis, J. J. \& Weingast, B. R. (2009).Violence and Social Orders: A Conceptual Framework for Interpreting Recorded Human History. Cambridge: Cambridge University Press.

Oficina Nacional de Estadística e Información (ONEI) (2015). Anuario estadístico de Cuba, 2014. La Habana: ONEI.

PÉREZ DE LA Riva, J. (1970). La contradicción fundamental de la sociedad colonial cubana: Trabajo esclavo contra trabajo libre. Economía y Desarrollo, (2), 144-154.

SAGRA, R. DE LA (1831). Historia económico-política y estadística de la isla de Cuba: O sea de sus progresos en la población, la agricultura, el comercio y las rentas. Habana: Impr. de las viudas de Arazoza y Soler.

SAn MARful, E. (2007). Población y poblamiento en la provincia de Matanzas: Sus relaciones con la agroindustria azucarera, siglos XVI-XXI. Novedades en población, 3 (5).

SANTAMARÍA, A. (2014). Revisión crítica de los estudios recientes sobre el origen y la transformación de la Cuba colonial azucarera y esclavista. América Latina en la Historia 
Económica, 21 (2), 168-198.

SCHNEIDER, E. (2015). African Slavery and Spanish Empire: Imperial Imaginings and Bourbon Reform in Eighteenth-Century. Fournal of Early American History, 5 (1), 3-29.

ScotT, R. (1985). Slave Emancipation in Cuba:The Transition to Free Labor, 1860-1899. Princeton: Princeton University Press.

SeIjas, T. \& Sierra, P. M. (2016). The Persistence of the Slave Market in SeventeenthCentury Central Mexico. Slavery \& Abolition. A fournal of Slave and Post-Slave Studies, 37 (2), 307-333.

Sokoloff, K. L. \& Engerman, S. L. (2000). History Lessons: Institutions, Factor Endowments, and Paths of Development in the New World. The Fournal of Economic Perspectives, 14 (3), 217-232.

TORNERO, P. (1996). Crecimiento económico y transformaciones sociales: Esclavos, hacendados y comerciantes en la Cuba colonial (1760-1840). Madrid: Ministerio de Trabajo y Seguridad Social. 


\section{ANEXO}

Series anuales de nacimientos, defunciones, inmigración, propietarios y esclavos registrados en los libros sacramentales de la parroquia

de San Carlos de Matanzas, 1755-1810

\begin{tabular}{|c|c|c|c|c|c|c|}
\hline Años & Nacimientos & Defunciones & Migración forzada & Total de entradas & Propietarios & Esclavos \\
\hline 1755 & 38 & & 11 & 49 & 12 & 38 \\
\hline 1756 & 37 & & 2 & 39 & 12 & 28 \\
\hline 1757 & 33 & & 2 & 35 & 6 & 8 \\
\hline 1758 & 36 & & 4 & 40 & 2 & 5 \\
\hline 1759 & 39 & & 6 & 45 & 9 & 34 \\
\hline 1760 & 29 & & 22 & 51 & 19 & 38 \\
\hline 1761 & 26 & & 8 & 34 & 14 & 29 \\
\hline 1762 & 38 & 31 & 6 & 44 & 16 & 33 \\
\hline 1763 & 40 & 31 & 69 & 109 & 17 & 100 \\
\hline 1764 & 28 & 41 & 96 & 124 & 13 & 109 \\
\hline 1765 & 40 & 40 & 24 & 64 & 22 & 53 \\
\hline 1766 & 35 & 46 & 17 & 52 & 15 & 30 \\
\hline 1767 & 43 & 39 & 9 & 52 & 19 & 36 \\
\hline 1768 & 39 & 54 & 6 & 45 & 17 & 32 \\
\hline 1769 & 46 & 72 & 10 & 56 & 21 & 34 \\
\hline 1770 & 50 & 56 & 11 & 61 & 16 & 30 \\
\hline 1771 & 52 & 60 & 13 & 65 & & \\
\hline 1772 & 50 & 47 & 12 & 62 & & \\
\hline 1773 & 42 & 42 & 7 & 49 & & \\
\hline 1774 & 52 & 67 & 6 & 58 & & \\
\hline 1775 & 52 & 57 & 8 & 60 & & \\
\hline 1776 & 51 & 50 & 8 & 59 & & \\
\hline 1777 & 46 & 49 & 9 & 55 & & \\
\hline 1778 & 35 & 66 & 33 & 68 & & \\
\hline 1779 & 49 & 60 & 19 & 68 & & \\
\hline 1780 & 55 & 52 & 28 & 83 & 19 & 54 \\
\hline 1781 & 63 & 67 & 8 & 71 & 17 & 40 \\
\hline 1782 & 48 & 57 & 5 & 53 & 20 & 33 \\
\hline 1783 & 51 & 48 & 8 & 59 & 21 & 37 \\
\hline 1784 & 55 & 37 & 39 & 94 & 33 & 75 \\
\hline 1785 & 58 & 40 & 34 & 92 & 34 & 67 \\
\hline 1786 & 71 & 31 & 11 & 82 & 37 & 60 \\
\hline 1787 & 63 & 42 & 18 & 81 & 36 & 57 \\
\hline
\end{tabular}




\begin{tabular}{|c|c|c|c|c|c|c|}
\hline Años & Nacimientos & Defunciones & Migración forzada & Total de entradas & Propietarios & Esclavos \\
\hline 1788 & 57 & 45 & 16 & 73 & 33 & 49 \\
\hline 1789 & 79 & 54 & 35 & 114 & 45 & 68 \\
\hline 1790 & 66 & 49 & 39 & 105 & 50 & 75 \\
\hline 1791 & 89 & 56 & 21 & 110 & 57 & 80 \\
\hline 1792 & 84 & 56 & 36 & 120 & 62 & 84 \\
\hline 1793 & 81 & 56 & 36 & 117 & 57 & 75 \\
\hline 1794 & 93 & 60 & 36 & 129 & 54 & 90 \\
\hline 1795 & 96 & 119 & 95 & 191 & 68 & 148 \\
\hline 1796 & 87 & 96 & 119 & 206 & 69 & 168 \\
\hline 1797 & 112 & 126 & 140 & 252 & 80 & 205 \\
\hline 1798 & 82 & 83 & 113 & 195 & 74 & 170 \\
\hline 1799 & 91 & 86 & 78 & 169 & 66 & 143 \\
\hline 1800 & 79 & 96 & 153 & 232 & & \\
\hline 1801 & 90 & 104 & 142 & 232 & & \\
\hline 1802 & 107 & 161 & 91 & 198 & & \\
\hline 1803 & 94 & 128 & 140 & 234 & & \\
\hline 1804 & 116 & 138 & 168 & 284 & & \\
\hline 1805 & 140 & 109 & 86 & 226 & & \\
\hline 1806 & 117 & 135 & 114 & 231 & & \\
\hline 1807 & 146 & 114 & 151 & 297 & & \\
\hline 1808 & 137 & 112 & 162 & 299 & & \\
\hline 1809 & 144 & 130 & 93 & 237 & & \\
\hline 1810 & 146 & 139 & 120 & 266 & & \\
\hline Totales & 3.823 & 3.534 & 2.753 & 6.576 & 439* & 2.415 \\
\hline
\end{tabular}

$\star$ La cantidad total de propietarios no responde a la suma de los propietarios por año, ya que entre un año y otro se repiten los propietarios. El valor anual es el número de propietarios que bautizan esclavos en un año o una década.

Fuente: elaboración propia a partir de los libros de bautismos y entierros de la iglesia parroquial de San Carlos de Matanzas. 